\title{
Principles and techniques of imaging in identifying the substrate of ventricular arrhythmia
}

\author{
Mischa T. Rijnierse, $M D,{ }^{a}$ Cornelis P. Allaart, $M D, P h D,{ }^{a}$ and Paul Knaapen, MD, \\ $\mathrm{PhD}^{\mathrm{a}}$ \\ a Department of Cardiology and Institute for Cardiovascular Research (IcaR-VU), VU University \\ Medical Center, Amsterdam, The Netherlands
}

Received Oct 21, 2015; accepted Nov 10, 2015

doi: $10.1007 / \mathrm{s} 12350-015-0344-8$

Life-threatening ventricular arrhythmias (VA) are a major cause of death in patients with cardiomyopathy. To date, impaired left ventricular ejection fraction remains the primary criterion for implantable cardioverter-defibrillator therapy to prevent sudden cardiac death. In recent years, however, advanced imaging techniques such as nuclear imaging, cardiac magnetic resonance imaging, and computed tomography have allowed for a more detailed evaluation of the underlying substrate of VA. These imaging modalities have emerged as a promising approach to assess the risk of sudden cardiac death. In addition, non-invasive identification of the critical sites of arrhythmias may guide ablation therapy. Typical anatomical substrates that can be evaluated by multiple advanced imaging techniques include perfusion abnormalities, scar and its border zone, and sympathetic denervation. Understanding the principles and techniques of different imaging modalities is essential to gain more insight in their role in identifying the arrhythmic substrate. The current review describes the principles of currently available imaging techniques to identify the substrate of VA.

Key Words: SPECT $\cdot$ PET imaging $\cdot$ computed tomography $(C T) \cdot$ magnetic resonance imaging $\cdot$ ventricular tachycardia

\begin{tabular}{|c|c|c|c|}
\hline \multicolumn{2}{|c|}{ Abbreviations } & $\mathrm{NE}$ & Norepineprhine \\
\hline CT & Computed tomography & PET & Positron emission tomography \\
\hline FDG & Fluorodeoxyglucose & SCD & Sudden cardiac death \\
\hline HED & Hydroxyephedrine & SI & Signal intensity \\
\hline $\mathrm{H} / \mathrm{M}$ & Heart to mediastinum & SPECT & Single-photon emission \\
\hline LGE- & Late gadolinium enhanced-cardiac & & tomography \\
\hline CMR & magnetic resonance imaging & VA & Ventricular arrhythmia \\
\hline LV & Left ventricle & VT & Ventricular tachycardia \\
\hline LVEF & Left ventricular ejection fraction & WR & Washout rate \\
\hline MBF & Myocardial blood flow & & \\
\hline MIBG & Metaiodobenzylguanide & & \\
\hline
\end{tabular}

Reprint requests: Paul Knaapen, MD, PhD, Department of Cardiology and Institute for Cardiovascular Research (IcaR-VU), VU University Medical Center, De Boelelaan 1117, 1081 HV, Amsterdam, The Netherlands; p.knaapen@vumc.nl

J Nucl Cardiol 2016;23:218-34.

$1071-3581 / \$ 34.00$

Copyright () 2015 The Author(s). This article is published with open access at Springerlink.com

\section{INTRODUCTION}

Sudden cardiac death (SCD) is a major health problem as it accounts for half of total cardiac mortality with an annual incidence of approximately 100 per 100.000 in the general population. ${ }^{1,2}$ In most cases, SCD 
is caused by ventricular arrhythmia (VA) in patients who suffer from underlying structural heart disease including ischemic cardiomyopathy, dilated cardiomyopathy, and hypertrophic cardiomyopathy. ${ }^{1}$ Implantable cardioverter-defibrillators (ICDs) have led to a significant reduction in mortality and have become standard clinical practice for the primary prevention of SCD in patients with left ventricular ejection fraction (LVEF) $<30-35 \%$, depending on cardiomyopathy etiology and heart failure symptoms. ${ }^{3-5}$ There are, however, several downsides of patient selection according to $\mathrm{LVEF}$ only. Recent studies have revealed that only $11-35 \%$ of patients with ICDs implanted for primary prevention of SCD actually receive appropriate ICD therapy in the ensuing years. ${ }^{6-8}$ It is clear that impairment of global LVEF is merely an indirect and aspecific risk factor for SCD, which is actually the result of underlying structural abnormalities causing electrical instability. A more detailed evaluation of the anatomical substrate of arrhythmias has therefore been an emerging topic of research over the last decade. Advanced cardiac imaging modalities such as nuclear imaging, cardiac magnetic resonance (CMR) imaging, and computed tomography (CT) hold great promise in evaluating the arrhythmic substrate to enhance risk stratification..$^{9-11}$ More recently, these imaging modalities have also been used to identify critical sites of ventricular tachycardia (VT) in order to guide electrophysiological ablation therapy. ${ }^{12-17}$ It is therefore important to understand the principles of these imaging techniques used to identify the arrhythmic substrate. This review discusses the principles and techniques of currently available advanced imaging techniques in identifying the substrate for ventricular arrhythmias.

\section{IMAGING TARGETS OF THE ARRHYTHMIC SUBSTRATE}

The pathophysiology of VA is complex and multifactorial. Traditionally, they are believed to be the result of a complex interplay between an anatomical substrate and transient triggers leading to electrical instability including increased automaticity, triggered activity, and re-entry. ${ }^{18}$ In more than $75 \%$ of SCD cases in the Western world, ischemic heart disease is responsible for the underlying arrhythmic substrate. ${ }^{1}$ Frequent culprits of susceptibility for VA are the presence of myocardial ischemia, scar burden, and sympathetic denervation. ${ }^{19}$ Various non-invasive imaging modalities have the potential to target these pathophysiological processes (Figure 1). Perfusion abnormalities may induce ischemia during an acute coronary syndrome or in the setting of chronic ischemic heart disease. In both scenarios, variations in myocardial perfusion may result in phases of ischemia and reperfusion which are associated with triggered activity and re-entry. ${ }^{19-21}$ The relation between ischemia and VA has been demonstrated in clinical studies. ${ }^{22,23}$ Nuclear imaging and CMR are considered to be the mainstay in perfusion imaging and therefore can be performed to identify the role of ischemia in the VA substrate. After myocardial infarction, inexcitable scar tissue is formed, surrounded by a border zone area with a mixture of viable myocytes and non-viable fibrous tissue. Consequently, this area comprises the fundamentals of a re-entry arrhythmia; heterogeneous prolonged conduction within the border zone adjacent to non-conduction scar tissue. ${ }^{24,25}$ This well-known theory has been supported by clinical studies demonstrating the association between the extent of scarring and susceptibility for $\mathrm{VA}^{26}$ In fact, the infarct borderzone is generally considered as the pivotal

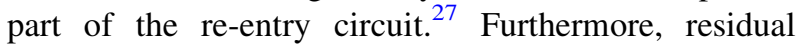
perfusion abnormalities in the infarct border zone may contribute to the arrhythmic vulnerability. ${ }^{28}$ Late gadolinium enhanced (LGE)-CMR is the preferred modality for scar and border zone visualization with high spatial resolution. Myocardial infarction does not merely result in a loss of myocytes but causes injury of cardiac sympathetic nerves to an even greater extent as nerve endings are more vulnerable to ischemia. ${ }^{29}$ Areas of denervated but viable myocardium are characterized by prolonged refractory periods and supersensitivity to catecholamines that cause increased heterogeneity in repolarization. ${ }^{30-33}$ Localized regions of hyperinnervation (nerve sprouting) due to increased heterogeneous post-injury regeneration have been observed in areas surrounding scar, which may further augment the electrical instability. ${ }^{34,35}$ Nuclear imaging is able to visualize cardiac sympathetic nerve function to assess the role of cardiac denervation. Finally, extensive scarring can initiate structural remodelling of the left ventricle (LV) resulting in loss of function, geometrical alterations, and increased wall stress. These structural changes itself have pro-arrhythmogenic effects due to modulation of action potential duration, calcium handling, and conduction. ${ }^{36,37}$

\section{NUCLEAR IMAGING}

Nuclear imaging provides the unique ability to target different pathophysiological aspects of the arrhythmic substrate, depending on the biological pathway of the utilized tracer. Consequently, nuclear techniques such as single photon emission computed tomography (SPECT) and positron emission tomography (PET) allow the evaluation of perfusion, scar, metabolism, and sympathetic innervation (Figure 2). Aspects of SPECT and PET techniques and image 

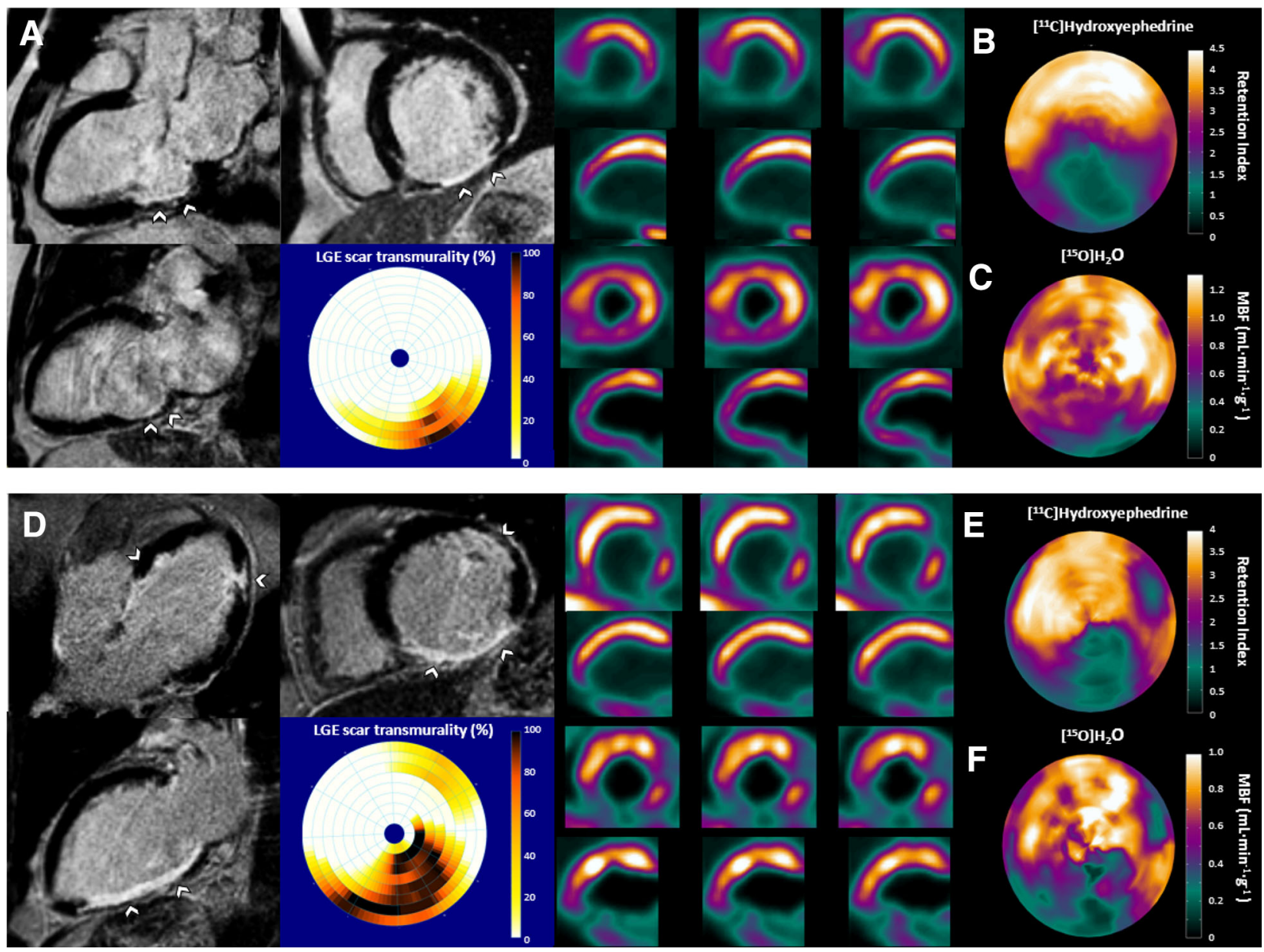

Figure 1. Imaging targets of the potential arrhythmic substrate in two patients with ischemic cardiomyopathy who were referred for ICD implantation for primary prevention of sudden cardiac death. $\left[{ }^{15} \mathrm{O}\right] \mathrm{H}_{2} \mathrm{O}$ PET, $\left[{ }^{11} \mathrm{C}\right]$ HED PET, and LGE-CMR of patient 1 (A-C) displayed a basal inferior wall myocardial infarction with contrast enhancement in this region (A) and a corresponding perfusion defect $(\mathbf{C})$ with a large innervation defect $(\mathbf{B})$ that exceeded the infarct size, resulting in a significant innervation-perfusion mismatch. Patient 2 (D-F) showed a large inferior wall myocardial infarction with transmural contrast enhancement as well as subendocardial contrast enhancement at the anterolateral wall (D) at LGE-CMR. $\left[{ }^{15} \mathrm{O}_{\mathrm{H}_{2}} \mathrm{O}\right.$ PET and $\left[{ }^{11} \mathrm{C}\right] \mathrm{HED}$ PET displayed corresponding perfusion and innervation defects with only limited innervation-perfusion mismatch. $C M R$, cardiovascular magnetic resonance; $L G E$, late gadolinium enhancement; $P E T$, positron emission tomography.

analysis with regard to the evaluation of the arrhythmic substrate are discussed below.

\section{Myocardial Perfusion Imaging}

To date, the most widely used nuclear imaging technique to evaluate the extent and location of myocardial perfusion abnormalities is SPECT. Frequently used SPECT tracers in clinical practice include ${ }^{201} \mathrm{TI}$, $\left[{ }^{99 \mathrm{~m}} \mathrm{Tc}\right]$ tetrofosmin, and $\left[{ }^{99 \mathrm{~m}} \mathrm{Tc}\right]$ sestamibi. Based on relative tracer uptake in the myocardium during resting conditions and exercise or pharmacologically induced stress, information is obtained on the size of resting perfusion defects (reflecting scar or hibernating myocardium), stress perfusion defects (reflecting scar, hibernating myocardium and/or ischemia), and their reversibility (reflecting ischemia). ${ }^{38,39}$ Observational studies have demonstrated that the inducibility of VA during an electrophysiological study is related to the presence and size of resting perfusion defects in patients with ischemic cardiomyopathy. ${ }^{40,41}$ Moreover, inducible VTs were found to originate close to the border of resting perfusion defects as observed by McFarland et $\mathrm{al},{ }^{42}$ highlighting the importance of infarct border zone. These results were confirmed in a recent study by Tian et $\mathrm{a}^{15}$ who reconstructed 3D scar models obtained 
A

Flow $\left({ }^{13} \mathrm{NH}_{3}\right)$

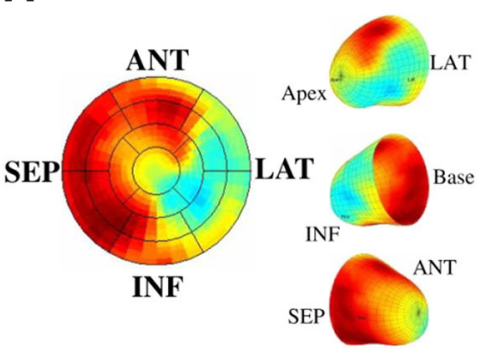

B

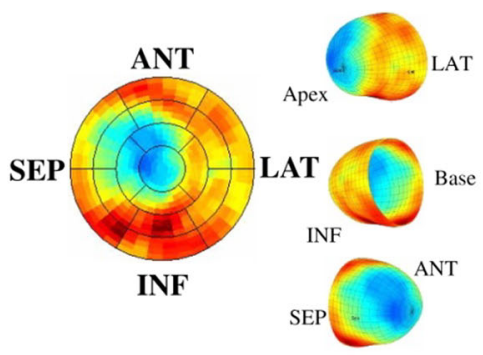

Viability $\left({ }^{18} \mathrm{FDG}\right)$
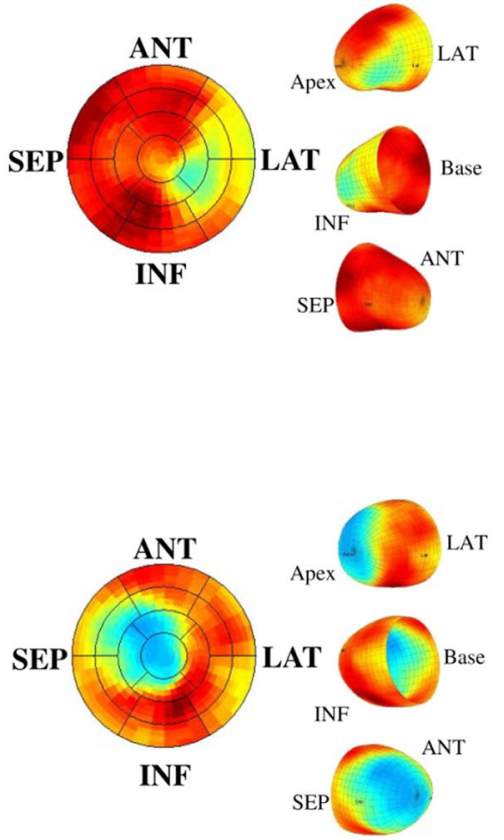

Sympathetic Innervation ( ${ }^{11} \mathrm{C}$-HED)

Figure 2. Examples of PET assessed perfusion, sympathetic innervation, and metabolism using different PET tracers in two patients with ischemic cardiomyopathy who were referred for primary prevention ICD therapy. (A) PET imaging revealed a mismatch between defects of perfusion and viability (infarct size), reflecting hibernating myocardium, as well as a mismatch between sympathetic innervation defect and infarct size, reflecting denervated but viable myocardium. This patient experienced appropriate ICD discharge for a fast ventricular tachyarrhythmia in follow-up. (B) PET imaging revealed matched defects of perfusion, viability, and sympathetic innervation. $A N T$, anterior; $I C D$, implantable cardioverter-defibrillator; $I N F$, inferior; $L A T$, lateral; PET, positron emission tomography; SEP, septum. Reprint with permission. ${ }^{63}$

from ${ }^{201}$ TI SPECT to identify voltage-defined scar, border zone, and normal myocardium during electroanatomic mapping in order to guide VT ablations. It was demonstrated that impairment of ${ }^{201} \mathrm{TI}$ uptake could accurately predict endocardial voltage-defined scar, which was the site of successful ablation in all patients (Figure 3). Most critical sites of VT were located within $1 \mathrm{~cm}$ of the SPECT assessed scar border, although the degree of ${ }^{201}$ TI uptake was not able to distinguish voltage defined scar and border zone. This may be the result of the relatively low spatial resolution of SPECT, limiting its value in border zone assessment. Nonetheless, a more recent retrospective analysis by Zhou et $\mathrm{al},{ }^{43}$ proposed a novel method of scar border zone evaluation using ${ }^{99 \mathrm{~m}}$ Tc SPECT by calculating the size of myocardium with uptake between $40 \%$ and $60 \%$ of peak myocardial uptake surrounding the scar core area (defined as $<40 \%$ of peak uptake) after comparing with template scans of healthy control patients. Interestingly, SPECT assessed border zone was shown to be significantly larger in patients who showed inducible sustained VA during an electrophysiological study as compared with non-inducible patients. The study, however, did not assess the site of origin of the induced VAs. ${ }^{43}$ Further studies are needed to evaluate the role of SPECT assessed border zone in identifying the arrhythmic substrate.

Residual ischemia after myocardial infarction may contribute to the electrical instability of the myocardium. This was revealed in a study by Paganelli et $\mathrm{al}^{44}$ who found a significant relation between the inducibility of VA and the presence and extent of residual ischemia as evaluated by stress-rest ${ }^{201}$ TI SPECT, in particular within the infarct area. No differences in fixed perfusion defects were observed, suggesting that residual ischemia might lead to additional vulnerability to VA.

For detecting perfusion abnormalities, PET provides advantages over SPECT including higher spatial resolution and the ability of absolute quantification of myocardial blood flow (MBF). Furthermore, commonly used PET perfusion tracers such as $\left[{ }^{15} \mathrm{O}\right] \mathrm{H}_{2} \mathrm{O}$, $\left[{ }^{13} \mathrm{~N}\right] \mathrm{NH}_{3}$, and ${ }^{82} \mathrm{Rb}$ have a higher extraction fraction 

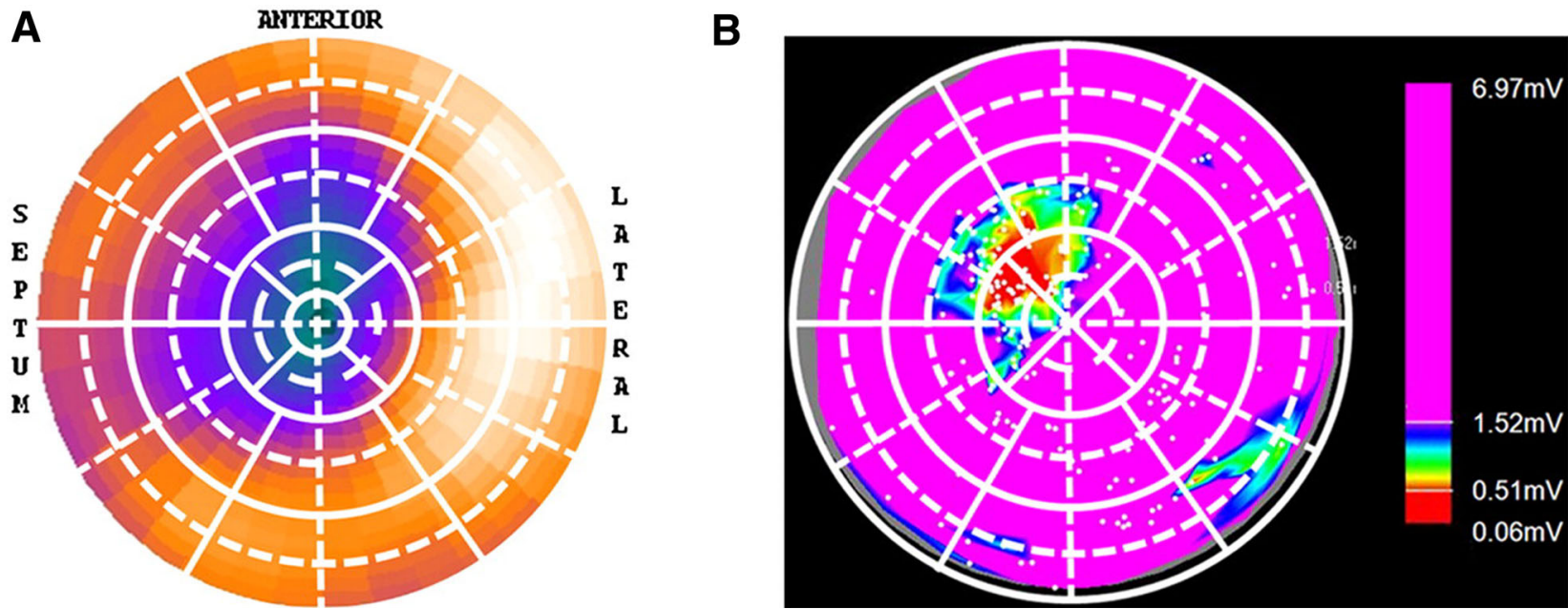

Figure 3. Example of ${ }^{201}$ TI SPECT assessed perfusion polar map (A) and corresponding electroanatomic voltage map (B) in a patient with ischemic cardiomyopathy. (A) SPECT polar map demonstrates anteroseptal and apical perfusion deficit which corresponded with the anteroseptal low-voltage scar area (red) as revealed by the corresponding voltage map (B). SPECT, singlephoton emission computed tomography. Reprint with permission. ${ }^{15}$

and short physical half-life. ${ }^{45}$ As a result, more subtle regional perfusion abnormalities can be detected and quantified in $\mathrm{mL} \cdot \mathrm{min}^{-1} \cdot \mathrm{g}^{-1}$. Of the available PET tracers, $\left[{ }^{15} \mathrm{O}\right] \mathrm{H}_{2} \mathrm{O}$ is considered the most ideal tracer for flow quantification as it is freely diffusible and metabolically inert with an extraction of $100 \%$ from arterial blood, whereas ${ }^{82} \mathrm{Rb}$ and $\left[{ }^{13} \mathrm{~N}^{-N} \mathrm{H}_{3}\right.$ are actively transported across the cell membrane with incomplete extraction and subsequently are metabolically trapped. ${ }^{46}$ Consequently, $\left[{ }^{15} \mathrm{O}_{\mathrm{H}} \mathrm{O}\right.$ PET quantifies MBF in viable tissue which is capable of exchanging water rapidly. ${ }^{47-49}$ This unique tracer characteristic might especially be of interest to assess subtle perfusion abnormalities in small areas of viable tissue within the infarct and border zone area which could provide more insight into the substrate and potential triggers of VA. A recently published pilot study demonstrated that impaired global hyperemic perfusion and coronary flow reserve as quantified by $\left[{ }^{15} \mathrm{O}_{\mathrm{H}} \mathrm{O}\right.$ PET were significantly related with VA inducibility during an electrophysiological study in 30 patients with ischemic cardiomyopathy who were referred for ICD implantation (Figure 4) ${ }^{28}$ These results need to be confirmed in larger studies to assess the relation between quantitative PET perfusion imaging and the VA substrate.

\section{Myocardial Metabolism}

Nuclear metabolic imaging to evaluate myocardial viability is commonly assessed using $\left[{ }^{18} \mathrm{~F}\right]$ fluorodeoxyglucose (FDG) PET in clinical practice. $\left[{ }^{18} \mathrm{~F}\right] \mathrm{FDG}$ is a glucose analogue which is taken up into the cardiomyocytes by glucose transporters and subsequently become trapped after being metabolized. Preserved $\left[{ }^{18} \mathrm{~F}\right]$ FDG uptake is considered a highly reliable marker for viable myocardium in patients with ischemic heart disease whereas severely reduced $\left[{ }^{18} \mathrm{~F}\right]$ FDG uptake indicates non-viable scar tissue. ${ }^{50}$ The assessment of scar tissue using $\left[{ }^{18} \mathrm{~F}\right] \mathrm{FDG}$ PET is well validated ${ }^{51,52}$ and good correlations have been observed with LGE-CMR assessed fibrosis ${ }^{53,54}$ (Figure 5). As such, it provides a valid approach to visualize the size and location of non-viable scar in order to evaluate the site of the arrhythmic substrate although it has not been studied frequently for this purpose. Nonetheless, a study performed by Dickfeld et al ${ }^{16}$ demonstrated that 3D scar maps as assessed using hybrid $\left[{ }^{18} \mathrm{~F}\right]$ FDG PET/CT fusion imaging could be integrated into clinical mapping system to visualize the 3D arrhythmogenic substrate in patients who were referred for VT ablation. A cut-off value of $<50 \%\left[{ }^{18} \mathrm{~F}\right] \mathrm{FDG}$ activity predicted voltage defined myocardial scar with a sensitivity and specificity of 89 and $93 \%$, respectively, whereas voltage defined infarct borderzone contained a mean metabolic activity of $67 \pm 15 \%$. These results imply that scar evaluation with $\left[{ }^{18} \mathrm{~F}\right] \mathrm{FDG}$ PET is able to identify critical arrhythmogenic substrates and may assist VT ablation therapies. ${ }^{55,56}$

When combined with perfusion imaging, viable myocardium can be further differentiated into the presence of subendocardial scar (mildly reduced $\left[{ }^{18} \mathrm{~F}\right] \mathrm{FDG}$ uptake and perfusion), hibernation (enhanced $\left[{ }^{18} \mathrm{~F}\right] \mathrm{FDG}$ uptake but impaired perfusion), and normal viable myocardium (preserved $\left[{ }^{18} \mathrm{~F}\right] \mathrm{FDG}$ and perfusion). 

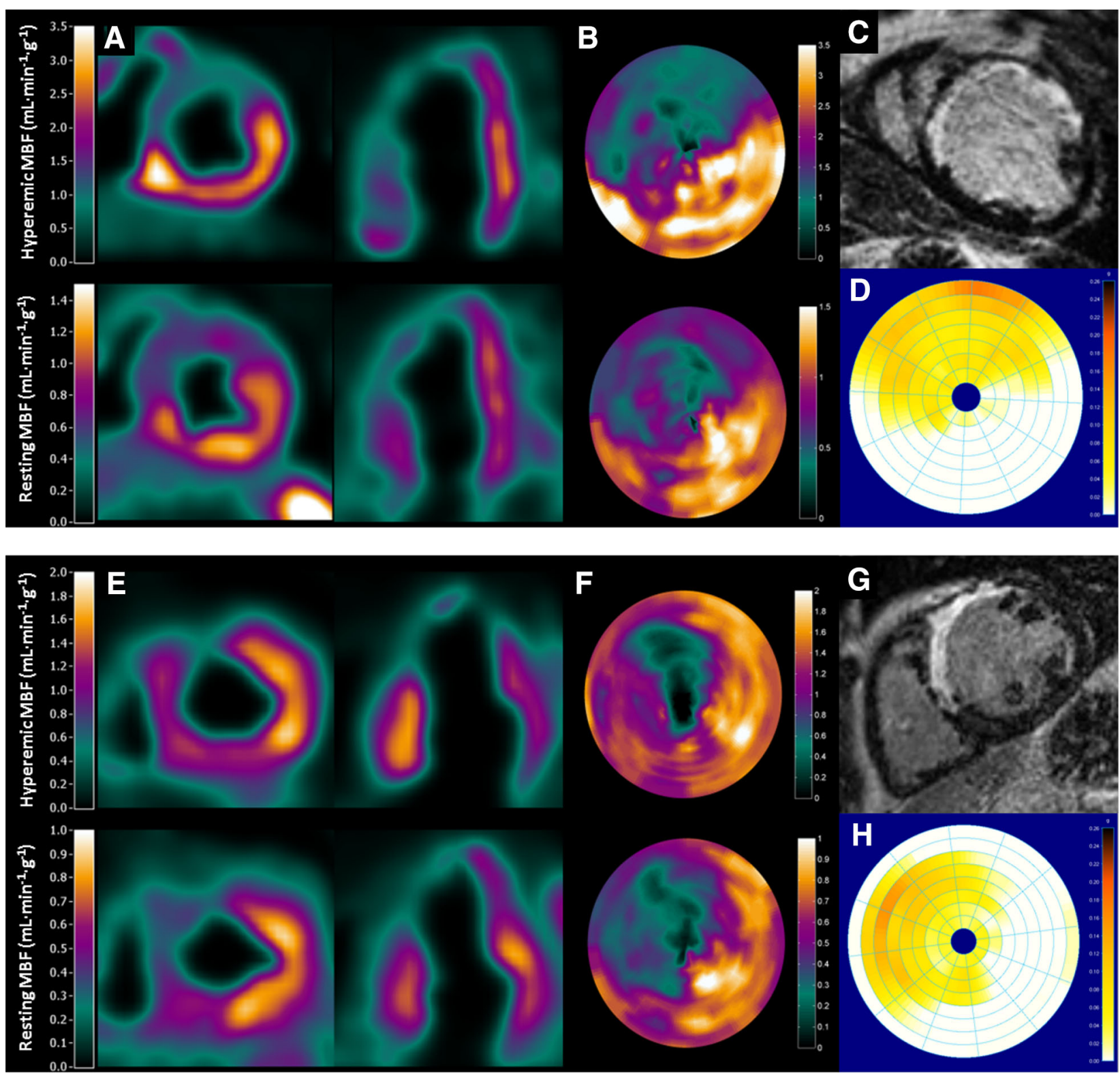

Figure 4. Examples of $\left[{ }^{15} \mathrm{O}_{\mathrm{H}} \mathrm{O}\right.$ PET and LGE-CMR scan in two patients with a history of an anterior wall myocardial infarction. Both patients displayed significant scar size $(\mathbf{C}, \mathbf{D}, \mathbf{G}$, and $\mathbf{H})$ and perfusion defect $(\mathbf{A}, \mathbf{B}, \mathbf{E}$ and $\mathbf{F})$ in the anteroseptal wall. However, quantitative MBF results showed significantly impaired hyperemic $\mathrm{MBF}$ in patient 2 as compared with patient 1 . Note the difference in scaling on the PET images $(\mathbf{A}, \mathbf{B}, \mathbf{E}$, and $\mathbf{F})$ between both patients. Electrophysiological study showed no inducible ventricular arrhythmias in patient 1 (A-D) whereas in patient 2 (E-H) a monomorphic ventricular tachycardia was induced. $C M R$, cardiovascular magnetic resonance; $L G E$, late gadolinium enhancement; $M B F$, myocardial blood flow; $P E T$, positron emission tomography. Reprint with permission. ${ }^{28}$

The detection of increased uptake in hibernating myocardium is based on a metabolic shift from fatty acid to glucose consumption as the myocytes are hypoperfused and become dependent on anaerobic metabolism. ${ }^{57}$ Chronic repetitive ischemia in hibernating myocardium may lead to electrical remodeling due to adaptive responses of the myocytes which can contribute to VA susceptibility. ${ }^{58}$ Preclinical studies suggest that this process consists of cellular hypertrophy, altered calcium handling, and prolongation of action potentials leading to triggered activity and heterogeneous repolarization. ${ }^{58-61}$ Clinical studies, however, 

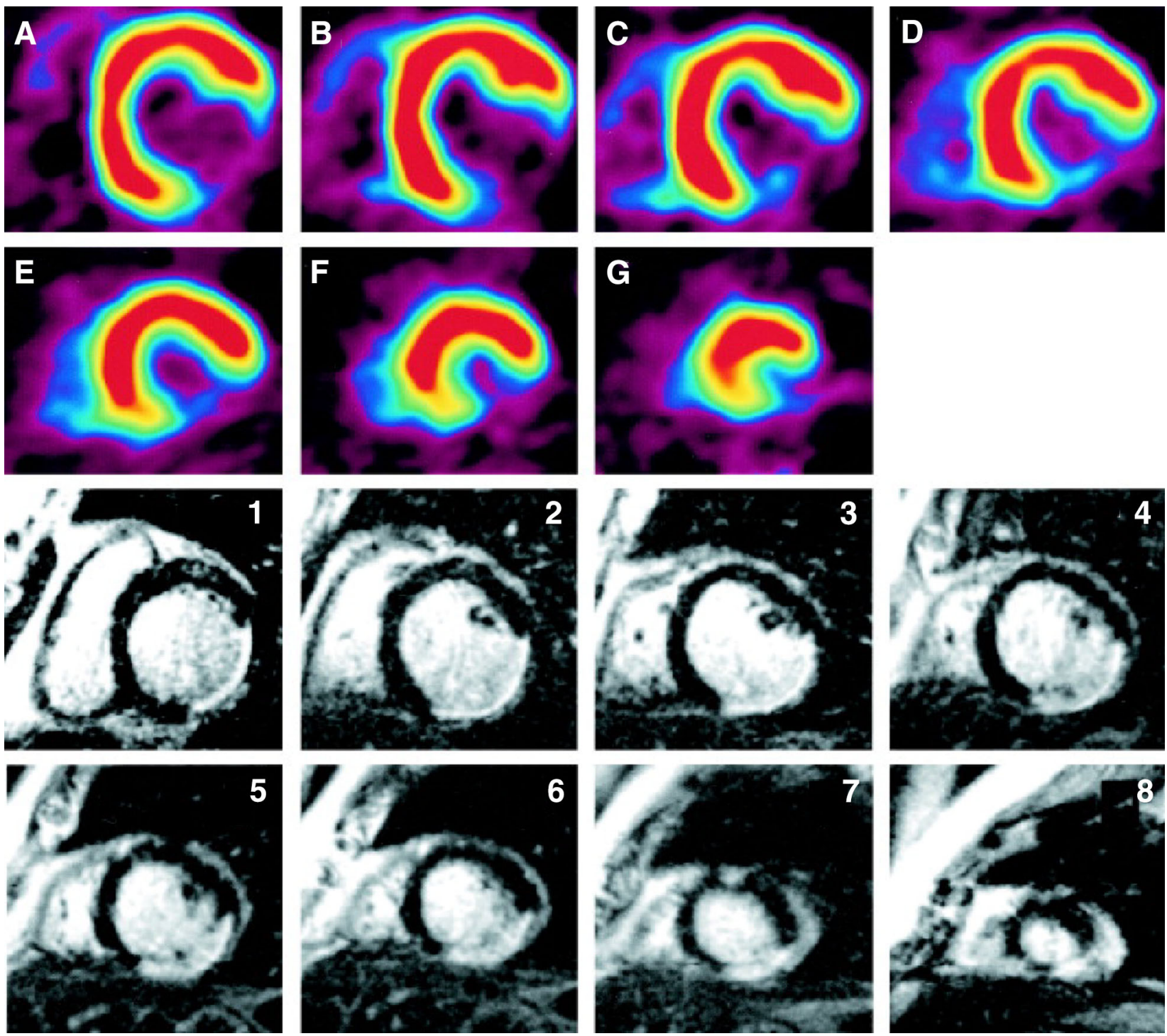

Figure 5. Example of $\left[{ }^{18} \mathrm{~F}\right] \mathrm{FDG}$ PET and LGE-CMR in a patient with a posterolateral myocardial infarction. The $\left[{ }^{18}\right.$ F]FDG PET images (A-G, base to apex) revealed a defect in the posterolateral wall extending to the inferior wall at the midventricular level. LGE-CMR (1-8, base to apex) shows transmural enhancement of a similar size in the same location. $C M R$, cardiovascular magnetic resonance; $L G E$, late gadolinium enhancement; $P E T$, positron emission tomography. Reprint with permission. $^{53}$

have reported inconsistent results linking the amount of hibernation to the actual occurrence of VA in followup. $^{62,63}$

\section{Sympathetic Innervation}

Targeting the cardiac sympathetic innervation using nuclear imaging has become an emerging approach to visualize the VA substrate. As discussed, the sympathetic nervous system may give rise to VA in several pathophysiological pathways including increased global sympathetic activity and regional cardiac sympathetic denervation resulting from ischemia, hibernation, or infarction. ${ }^{64}$ The mainstay of innervation imaging is based on the uptake, storage, and release of norepinephrine (NE), which is mediated by presynaptic sympathetic nerve terminals in response to variations of sympathetic drive. The sympathetic neurotransmitter NE is produced within sympathetic nerve terminals and stored in vesicles. After sympathetic activation, it is released into the sympathetic nerve cleft where it is able to bind on beta-adrenergic receptors of myocytes to 

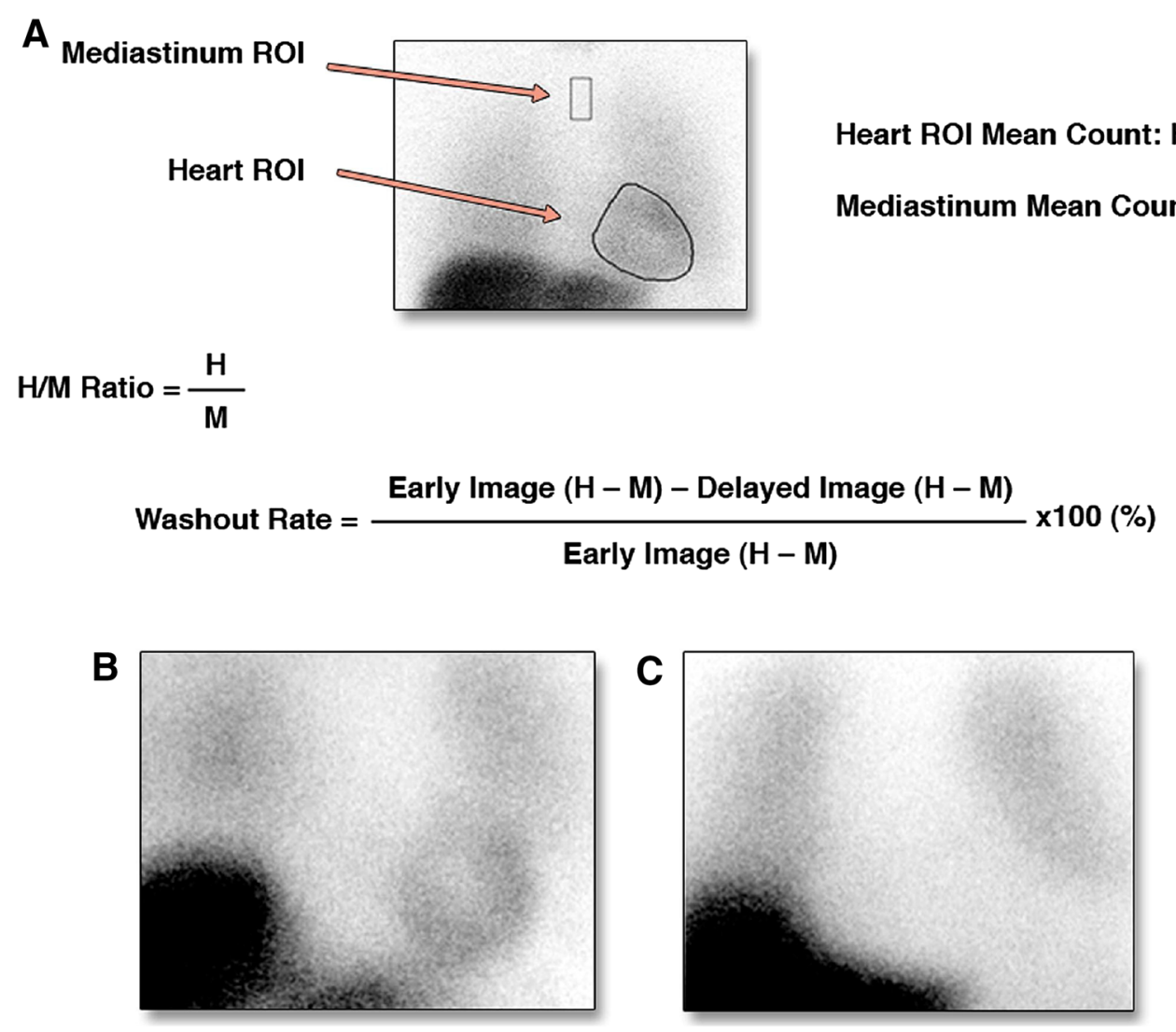

Figure 6. Example of global $\left[{ }^{123} \mathrm{I}\right] \mathrm{MIBG} \mathrm{H} / \mathrm{M}$ ratio and wash-out rate calculation on planar $\left[{ }^{123} \mathrm{I}\right] \mathrm{MIBG}$ imaging (A), and examples of normal cardiac $\left[{ }^{123} \mathrm{I}\right] \mathrm{MIBG}$ activity in a patient with $\mathrm{H} /$ $\mathrm{M}$ ratio of $1.80(\mathbf{B})$ compared with a $\left[{ }^{123} \mathrm{I}\right] \mathrm{MIBG}$ scan showing a significantly impaired $\left[{ }^{123} \mathrm{I}\right] \mathrm{MIBG}$ activity with $\mathrm{H} / \mathrm{M}$ ratio of $1.10(\mathbf{C})$. H/M, heart-to-mediastinum. Reprint with permission. ${ }^{70}$

transmit their sympathetic effects. ${ }^{65}$ Most of the NE, however, is cleared from the synaptic cleft, either by presynaptic neuronal re-uptake (uptake-1 mechanism), or by non-neuronal uptake by post synaptic transporters on myocytes (uptake-2 mechanism) ${ }^{66,67}$ After presynaptic re-uptake, NE is metabolized or stored back into the vesicles. Dependent on specific characteristics of the tracer used, several biological aspects of the neuronal function can be visualized. To date, most commonly used tracers are NE analogues $\left[{ }^{123} \mathrm{I}\right]$ metaiodobenzylguanide (MIBG) for SPECT and $\left[{ }^{11}\right.$ C]hydroxyephedrine (HED) for PET. Both tracers are resistant to metabolic enzymes and show high affinity for presynaptic NE uptake-1 allowing the visualization of presynaptic sympathetic nerve function. ${ }^{65,68}$ Other presynaptic PET tracers include $\left[{ }^{11} \mathrm{C}\right]$ epinephrine, $\left[{ }^{11} \mathrm{C}\right]$ phenylephrine, and ${ }^{18} \mathrm{~F}$-LMI1195 while $\left[{ }^{11} \mathrm{C}\right]$-CGP12177 is the most commonly used tracer for postsynaptic beta-adrenergic receptors. ${ }^{65,69}$

$\left[{ }^{123}\right.$ I]MIBG SPECT typically includes the assessment of early and delayed planar as well as tomographic images at 15-30 minutes and 3-4 hours after tracer injection, respectively. In planar images, global myocardial uptake is evaluated by calculating the heart to mediastinum $(\mathrm{H} / \mathrm{M})$ uptake ratio. Furthermore, $\left[{ }^{123} \mathrm{I}\right] \mathrm{MIBG}$ washout rate (WR) is defined as the difference between the early and delayed H/M ratios and primarily reflects presynaptic NE turnover, a marker for sympathetic activity (Figure 6). ${ }^{70}$ In patients with cardiomyopathy, increased sympathetic drive causing high nerve firings and insufficient re-uptake is reflected by a decrease in delayed $\mathrm{H} / \mathrm{M}$ ratio and increased WR. ${ }^{68}$ Assessment of size and location of regional innervation defects on tomographic delayed [ ${ }^{123}$ I]MIBG images allow more detailed evaluation of the anatomic substrate. Accordingly, Klein et $\mathrm{al}^{17}$ recently acquired 3D reconstructions of $\left[{ }^{123} \mathrm{I}\right] \mathrm{MIBG}$ SPECT and combined these innervation maps with endocardial voltage maps as assessed during electrophysiological study in patients with ischemic cardiomyopathy who were referred for VT ablation. Areas of cardiac denervation were found to be significantly larger as compared with voltage defined scar reflecting the higher vulnerability of cardiac nerves 


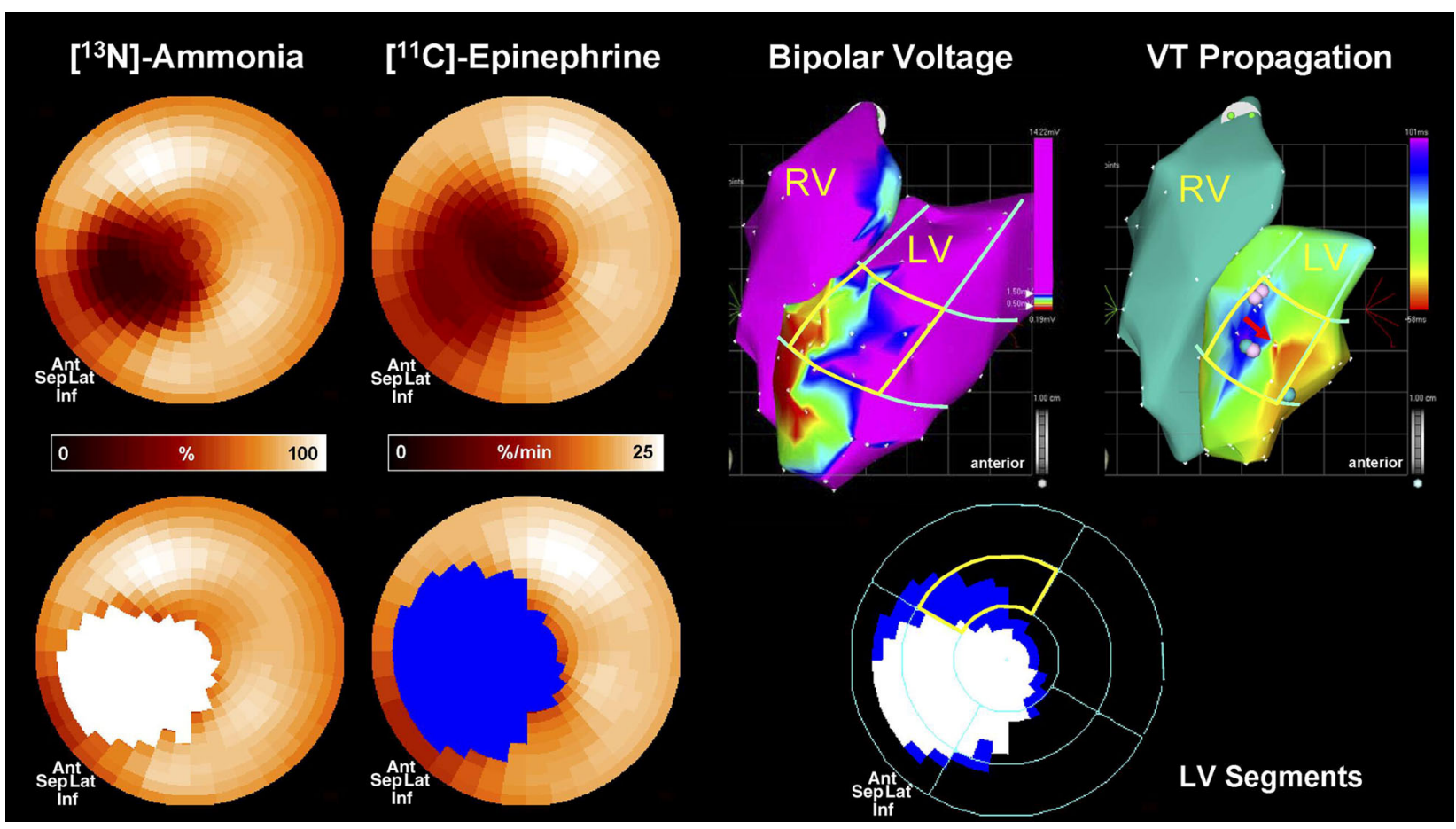

Figure 7. Electrophysiological study in an animal with inducible VT. PET assessed perfusion and innervation polarmaps demonstrated an innervation defect (blue) which exceeded the size of the perfusion defect (white), predominantly in the distal anterior wall segment (bottom right). Threedimensional electroanatomic voltage maps (top right) demonstrated reduced voltage in apex and distal anterior septal wall and propagation map showed earliest activation of the VT in the infarct border zone in the distal anterior wall (red arrow), which corresponded with the location of the innervation-perfusion mismatch. PET, positron emission tomography; VT, ventricular tachycardia. Reprint with permission. ${ }^{78}$

to ischemia. More importantly, all successful ablation sites were located in myocardium with abnormal $\left[{ }^{123}\right.$ I]MIBG uptake whereas in $36 \%$ these sites were found in normal myocardium when assessed with voltage mapping. These results indicate the role of sympathetic denervation as VA substrate, which may be more important than scar. When combined with SPECT perfusion imaging, regional areas of viable but denervated myocardium can be detected which are potential sites of electrical instability. ${ }^{71}$ In a pilot study, Bax and colleagues performed $\left[{ }^{123} \mathrm{I}\right] \mathrm{MIBG}$ and $\left[{ }^{99 \mathrm{~m}} \mathrm{Tc}\right]$ tetrofosmin SPECT in patients with ischemic cardiomyopathy who underwent electrophysiological testing. Patients with inducible VA showed larger areas of $\left[{ }^{123} \mathrm{I}\right] \mathrm{MIBG}$ defects obtained from delayed SPECT images. The mismatch size, however, between innervation and perfusion defects was not related to VA susceptibility. ${ }^{72}$ As areas of denervated but viable myocardium may be intertwined with the infarct border zone which often contains critical sites of VA, the assessment of $\left[{ }^{123} \mathrm{I}\right] \mathrm{MIBG}$ uptake in this area specifically may be of interest. Accordingly, in a post-hoc analysis of the previous mentioned study by $\mathrm{Bax}$ et al, $\left[{ }^{123} \mathrm{I}\right] \mathrm{MIBG}$ uptake in the infarct border zone defined using $\left[{ }^{99 \mathrm{~m}} \mathrm{Tc}\right]$ tetrofosmin SPECT predicted the inducibility of sustained VA during electrophysiological testing with higher accuracy compared with scar or scar border zone itself. ${ }^{43}$

The assessment of sympathetic innervation using PET may have incremental value in evaluating the arrhythmic substrate. First, the superior spatial resolution of PET results in more detailed assessment of regional sympathetic innervation and innervation/perfusion mismatch areas. Second, dynamic imaging protocols enables absolute quantification of sympathetic nerve retention of tracers. ${ }^{73}$ Third, the availability of multiple tracers, each acting on different biological aspects of the nerve terminals or beta-adrenergic receptors, provides further insight into the cardiac neuronal function. ${ }^{74}$ The $\left[{ }^{11} \mathrm{C}\right]$ HED PET protocol typically consists of a dynamic scan with a duration of 40-60 minutes after injection of the tracer. Subsequently, sympathetic nerve uptake is frequently quantified using the retention index, which is defined as the uptake in the final frame 

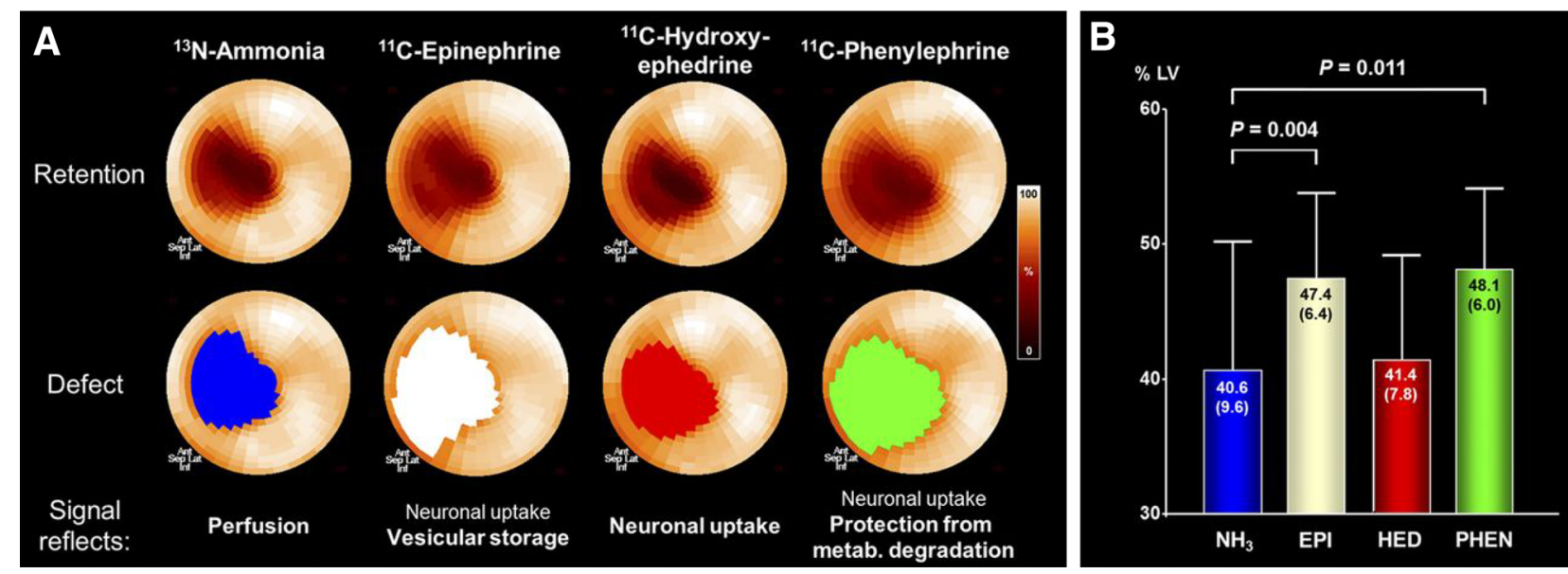

Figure 8. PET assessment of myocardial innervation using multiple radiolabeled catecholamine analogues in an animal with myocardial infarction. (A) Polar maps of representative infarct animal showing retention of 4 tracers (top), along with color-coded defect areas. Epinephrine and phenylephrine defects exceeded the perfusion defect, whereas hydroxyephedrine defect is comparable to the perfusion defect. (B) Bar chart showing group results of defect sizes. Ant, anterior; EPI, epinephrine; HED, hydroxyephedrine; Inf, inferior; Lat, lateral; metab., metabolic; NH3, ammonia; PET, positron emission tomography; PHEN, phenylephrine; sep, septal. Reprint with permission. $^{79}$

of the scan divided by the integral of the arterial input curve. ${ }^{75}$ In addition, kinetic modelling of the tracer may be performed which results in more absolute quantification of the volume of distribution of the tracer and its wash-out. ${ }^{73}$ Although $\left[{ }^{11} \mathrm{C}\right] \mathrm{HED}$ retention, washout and defect size are closely related to $\left[{ }^{123} \mathrm{I}\right] \mathrm{MIBG}$ SPECT variables, the ability of quantification may overcome problems with relative defect size calculations such as global downregulation in patients with heart failure. ${ }^{76}$ In addition, by calculating the influx rate $\left(\mathrm{K}_{1}\right)$ of $\left[{ }^{11} \mathrm{C}\right]$ HED, Harms et al recently demonstrated the feasibility of assessing perfusion and innervation defects to evaluate mismatch areas using a single dynamic $\left[{ }^{11} \mathrm{C}\right]$ HED PET scan. ${ }^{77}$ Several studies have showed altered electrophysiological characteristics within areas of reduced $\left[{ }^{11} \mathrm{C}\right] \mathrm{HED}$ uptake including prolonged refractoriness and supersensitivity to catecholamines. ${ }^{30,33}$ Sasano et $\mathrm{al}^{78}$ showed that the extent of viable but denervated myocardium quantified with $\left[{ }^{11} \mathrm{C}\right]$ epinephrine and $\left[{ }^{13} \mathrm{~N}\right] \mathrm{NH}_{3}$ PET was associated with inducible VTs in a porcine model. Importantly, the area of denervated but viable myocardium was related to the site of initiation of the induced VTs as well as decreased endocardial voltage obtained by voltage mapping (Figure 7). Recently, the uptake of multiple presynaptic tracers was explored in viable but devervated myocardium in a similar porcine myocardial infarction model. ${ }^{79}$ While $\left[{ }^{11} \mathrm{C}\right]$ epinephrine retention was impaired in the infarct border zone, $\left[{ }^{11} \mathrm{C}\right] \mathrm{HED}$ retention was relatively preserved, suggesting compromised vesicular storage rather than impaired uptake or complete denervation (Figure 8). In fact, immunohistology of explanted hearts showed intact nerve fibers and nerve sprouting in the infarct border zone. ${ }^{79}$ However, results from the PAREPET study confirmed the presence of larger $\left[{ }^{11} \mathrm{C}\right] \mathrm{HED}$ assessed denervation areas as compared to perfusion defects in patients with ischemic cardiomyopathy, which may reflect a more advance state of neuronal impairment in chronic ischemic heart disease. ${ }^{63}$ Next to injured presynaptic sympathetic nerves, patients with ischemic cardiomyopathy show abnormalities of the postsynaptic beta-adrenergic receptors, although to a lesser extent (Figure 9). Consequently, a mismatch between presynaptic and postsynaptic adrenergic signaling is present which might be vulnerable to arrhythmias due to locally increased levels of catecholamines affecting repolarization. ${ }^{80}$. Finally, abnormal $\left[{ }^{11} \mathrm{C}\right] \mathrm{HED}$ retention has been observed in non-ischemic cardiomyopathies ${ }^{81-83}$ as well as primary arrhythmogenic disorders. ${ }^{84-86}$

\section{CARDIAC MAGNETIC RESONANCE IMAGING}

CMR imaging is increasingly used in daily clinical practice to quantify left ventricular volumes and function. Due to superior accuracy and reproducibility, CMR is considered as gold standard for the evaluation of LV dimensions. ${ }^{87}$ Furthermore, 3D evaluation of LV geometry may provide insight in remodelling and regional wall stress, which is linked to VA ${ }^{88}$ In addition, contrast 
${ }^{11} \mathrm{C}-\mathrm{mHED}$

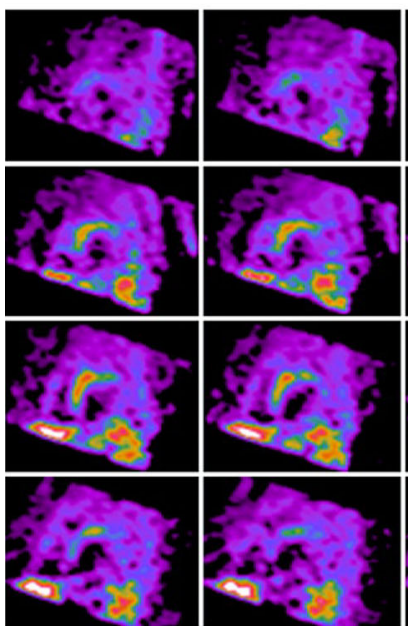

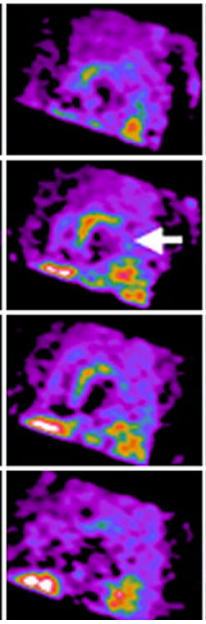

${ }^{11}$ C-CGP 12177

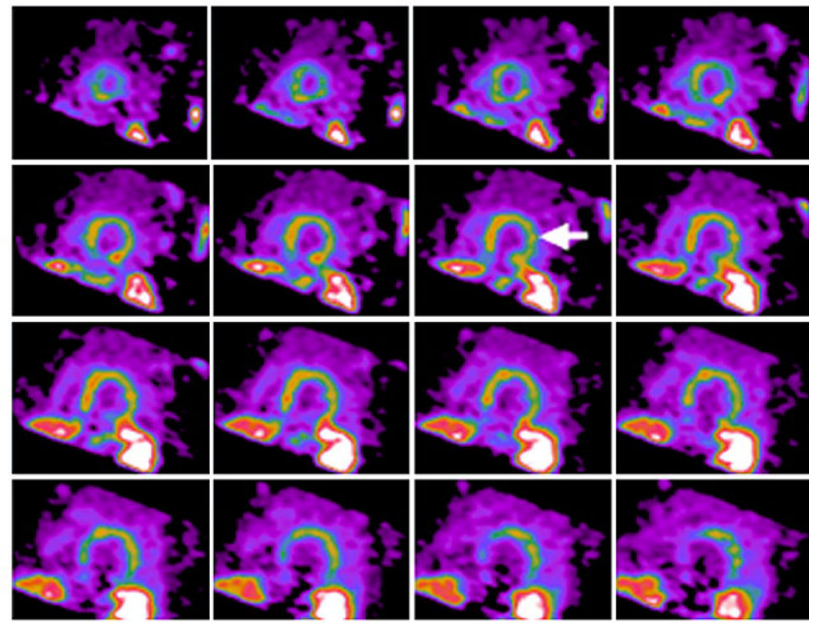

Figure 9. PET imaging of presynaptic sympathetic nerves using $\left[{ }^{11} \mathrm{C}\right] \mathrm{HED}$ and postsynaptic betaadrenergic receptors using $\left[{ }^{11} \mathrm{C}\right] \mathrm{CGP} 12177$ in a patient with ischemic cardiomyopathy. White arrows indicate extensive mismatch between presynaptic innervation and postsynaptic betaadrenergic receptors in the lateral wall. HED, hydroxyephedrine; PET, positron emission tomography. Reprint with permission. ${ }^{80}$

agents such as gadolinium enables qualitative and semiquantitative assessment of perfusion based on the washin of the contrast agent into the myocardium. By comparing first-pass perfusion during pharmacologically induced stress and resting conditions, ischemia can be detected. However, no studies have evaluated the role of CMR perfusion imaging in identifying the substrate of VA to date. The actual superior value of CMR in identifying the arrhythmic substrate is the ability of scar tissue characterization using LGE which will be discussed below.

\section{Late Gadolinium Enhancement}

The visualization of fibrotic tissue is based on alterations of $\mathrm{T} 1$ relaxation characteristics after intravenous contrast administration. Gadolinium diffuses out of the intravascular volume and after 10-15 minutes it is distributed within the extracellular tissue as it cannot enter the myocytes. Hence, magnetic characteristics in fibrotic tissue are altered resulting in a relatively higher signal intensity (SI), visible as bright areas when compared to the normal remote myocardium on the T1-weighted images. ${ }^{89}$ Scar tissue assessment using LGE-CMR has a high spatial resolution and is well validated in histopathologic studies. ${ }^{90,91}$ LGE can be quantified in absolute grams of scar tissue using the fullwith-at-half-maximum which defines scar core tissue as SI $>50 \%$ of maximum SI in hyperenhanced area, or using different SD thresholds (>3-5 SD) of the mean SI in remote myocardium. ${ }^{92}$ In addition, areas of intermediate enhancement ('the gray zone') can be assessed separately using various SI thresholds such as $35-50 \%$ of maximum SI or 2-3 SD of mean remote SI to evaluate the scar border zone which contains a heterogeneity of viable and non-viable tissue ${ }^{39,93}$ These different methodologies of quantification will result in significantly different absolute grams of scar core and scar border zone as demonstrated in Figure 10, although all seem related to the VA substrate. ${ }^{94,95}$ Bello et $\mathrm{al}^{26}$ was the first to describe the association between LGE-CMR assessed total scar size and inducibility of sustained VA in patients with ischemic cardiomyopathy. Subsequently, Schmidt et $\mathrm{al}^{96}$ reported that quantification of the heterogeneous scar size resulted in improved prediction of VT inducibility. In addition, the presence of nonischemic fibrosis is associated with VT inducibility in patients with dilated cardiomyopathy. ${ }^{97}$ Although these studies suggest a direct link between LGE scar characteristics and the arrhythmogenic substrate, they did not compare the location of scar or borderzone and the site of origin of the induced VA. This was explored in detail by more recent studies who evaluated patients that underwent VT ablation. Comparable to the described PET and SPECT studies, 3D reconstructions of LGE-CMR assessed scar can be integrated into electroanatomic mapping systems to visualize the arrhythmic substrate which may assist VT ablation strategies. ${ }^{12,13,98-103}$ For this purpose, LGE-CMR might be superior compared with other investigated imaging 

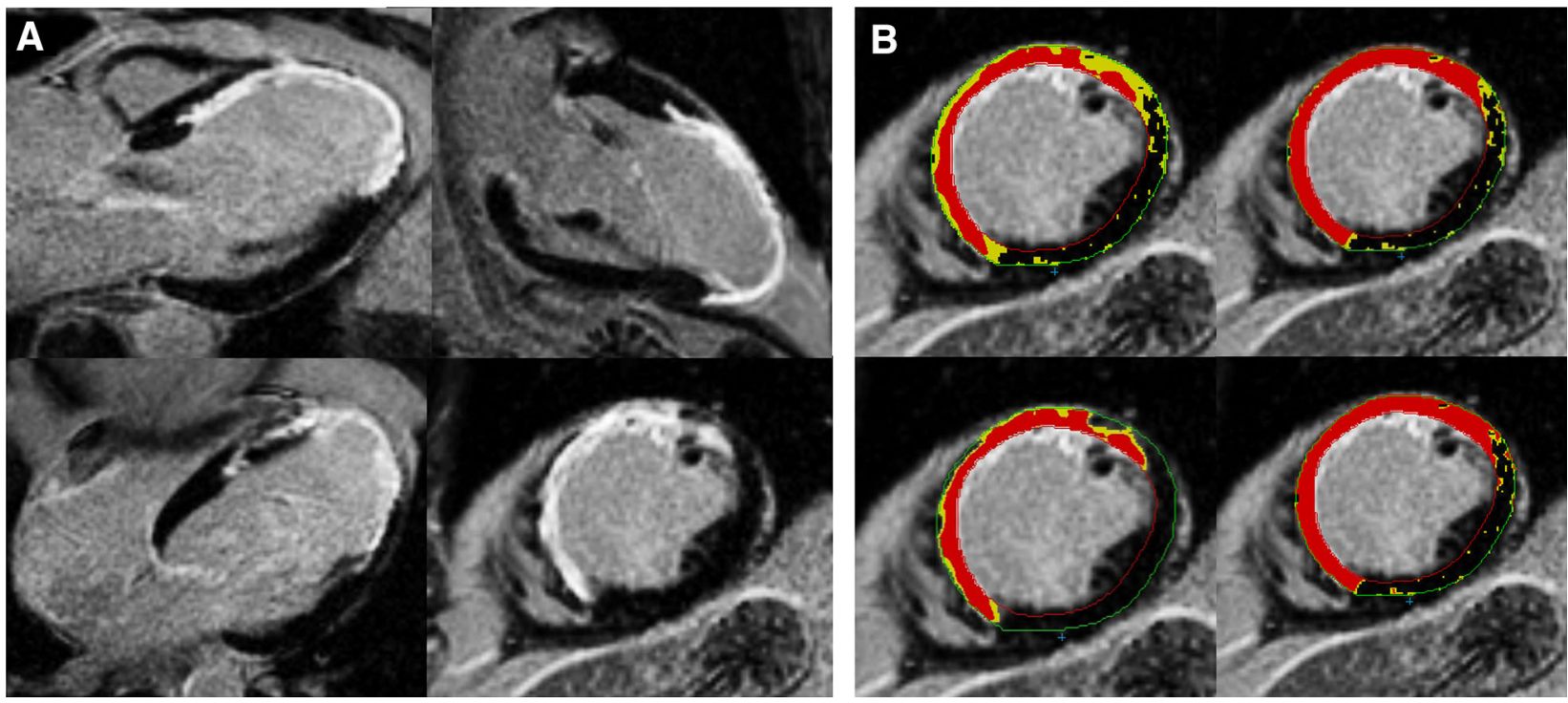

Figure 10. (A) Example of short and long axis LGE-CMR images in a patient with a large anterior wall myocardial infarction with contrast enhancement visible in the anteroseptal, anterior, and anterolateral wall. (B) Examples of several previously validated quantification methods of the scar core area (red) and scar border zone area (yellow), each resulting in significant a different scar core and border zone size.

modalities as it is able to discriminate between endocardial, midwall, and epicardial scar localizations, whereas invasive electroanatomic mapping only evaluates the endocardial or epicardial surface. ${ }^{104}$ By projecting the SI, transmural extension, or localization of scar acquired from consecutive LGE cine images onto 3D shells of the LV with coloured scales, 3D LGE maps are generated. Integration of 3D LGE with electroanatomic maps provide unique insight into LGE characteristics of critical sites of the VT. Desjardins et $\mathrm{al}^{101}$ showed that critical sites of postinfarction VT are located within areas of high contrast enhancement as assessed with LGE-CMR. In addition, Perez-David et $\mathrm{al}^{102}$ demonstrated that patients with ischemic heart disease and documented sustained VT frequently show continuous tissue corridors of border zone areas inside scar tissue on 3D endocardial SI maps (Figure 11). More importantly, these heterogeneous tissue corridors corresponded with the size and location of slow conduction channels as observed during voltage mapping and often were the critical isthmus site of VT. In another study using high resolution 3T LGE-CMR, 74\% of the critical isthmus sites of VTs were identified by border zone channels which were more commonly seen in the endocardium. $^{98}$ Other studies that integrated LGECMR in electroanatomic mapping demonstrated that critical sites of the VT circuit are often located very close to scar tissue with high transmural extension and/ or near the transition of scar core and border zone. ${ }^{12,99,100,104}$ The described studies provide evidence for the relation of LGE-CMR assessed scar characteristics and the VA substrate, in particular the location of infarct border zone and more transmurally extended scar tissue. Finally, a preclinical study performed by $\mathrm{Ng}$ et $\mathrm{al}^{105}$ showed the potential of performing a noninvasive virtual electrophysiological study in an in-vivo 3D LGE-CMR model using a computer simulation after applying a mathematical model that predicts VT circuits. It was demonstrated that most of the virtually induced VTs using CMR corresponded with actual inducible VTs during invasive electrophysiological study.

\section{T1 Mapping}

Several limitations of LGE-CMR should be acknowledged. First, standardization of imaging protocols and analyses is lacking as different SI thresholds are used for scar and border zone definitions. Second, LGE is based on relative differences in SI between fibrotic tissue and supposedly normal myocardium. Consequently, LGE is only able to detect focal areas of fibrotic tissue, whereas diffuse interstitial fibrosis cannot be identified. The occurrence of diffuse interstitial fibrosis, however, is not an infrequent pathological phenomenon in cardiomyopathy, not merely in nonischemic etiologies, but also in 'remote' areas of ischemic cardiomyopathy. ${ }^{106-109}$ More importantly, interstitial fibrosis may affect electrical propagation between myocytes due to alterations in cell-coupling, thereby contributing to the arrhythmic substrate. ${ }^{110} \mathrm{~T} 1$ mapping 


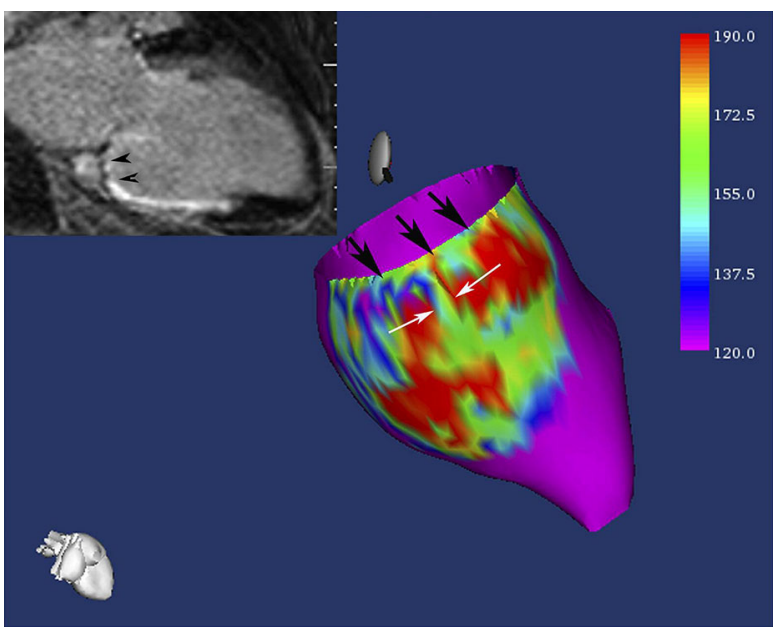

Figure 11. Example of signal intensity map of the subendocardial tissue projected onto a 3-dimensional endocardial shell reconstruction of the left ventricle. Scar core area with high signal intensity is presented in red, whereas normal myocardium is presented in purple. Black and white arrows indicate two corridors of continuous heterogeneous tissue with intermediate signal intensity (green) surrounded by scar tissue. The left upper corner shows the corresponding long-axis LGECMR image with heterogeneous tissue located between the mitral valve and the inferior scar (black arrowheads). CMR, cardiovascular magnetic resonance imaging; $L G E$, late gadolinium enhancement. Reprint with permission. ${ }^{102}$

has emerged as a new CMR technique to evaluate diffuse fibrosis as it provides a pixel-wise quantification of myocardial T1 values, thereby overcoming the limitations of LGE-CMR. By quantifying absolute native pre-contrast $\mathrm{T} 1$ as well as post-contrast $\mathrm{T} 1$ values, the extracellular volume index can be calculated which is closely correlated with histopathologic measures of diffuse fibrosis. ${ }^{106,108}$ Although it has recently been demonstrated that absolute $\mathrm{T} 1$ values may be linked to the occurrence of VA in ischemic and nonischemic cardiomyopathy, future studies are needed to confirm the role of diffuse fibrosis as assessed with T1 mapping in identifying the VA substrate ${ }^{111}$

\section{COMPUTED TOMOGRAPHY}

Contrast enhanced CT is an alternative modality for scar evaluation with high spatial and temporal resolution. Comparable to LGE-CMR, late enhancement CT can be acquired approximately 10 minutes after contrast injection with a standard single-energy or dual-energy cardiac CT. Both have been demonstrated to correlate well with LGE-CMR assessed scar as well as histopathologic findings ${ }^{112-115}$ In addition, perfusion defects obtained from qualitative first-pass CT perfusion imaging may provide information on the extent and location of scar. Few studies have assessed the role of contrast enhanced CT in identifying the arrhythmic substrate. Tian et $\mathrm{al}^{14}$ evaluated abnormalities in LV wall thickness, wall thickening, and perfusion using 3D contrast enhanced CT in 11 patients with ischemic cardiomyopathy who underwent VT ablation. Although all were related with abnormal endocardial voltage obtained from electroanatomic mapping, areas of CT hypoperfusion showed superior correlations with scar and border zone and represented the site of successful ablation in $82 \%$ of cases. It has been demonstrated that the size of both CT early hypoperfused and late hyperenhanced areas are comparable to LGE-CMR assessed scar size. ${ }^{113,116}$ Consequently, contrast enhanced CT may be used to identify the arrhythmic substrate in patients with ischemic cardiomyopathy. However, nephrotoxic effects of iodinated contrast and the occurrence of imaging artefacts resulting from metal devices may hinder its use in some cardiomyopathy patients.

\section{CONCLUSION}

Advanced non-invasive imaging techniques such as nuclear imaging, CMR, and CT have emerged during the past decades to evaluate multiple aspects of the substrate of VA. Typical imaging targets include myocardial perfusion abnormalities, hibernation, scar, scar border zone, and sympathetic innervation. Their role in identifying the origin of VA has been shown in multiple studies suggesting significant value in diagnosis and risk assessment of $\mathrm{VA}$, and a potential role in guiding ablation strategies. For detecting perfusion abnormalities, most experience has been gained using SPECT and PET, whereas LGE-CMR is the preferred modality for scar and border zone evaluation. More biological aspects of the arrhythmic substrate such as metabolism and sympathetic nerve function are well performed using PET. As targets of multiple imaging modalities may be intertwined, studies are warranted that compare imaging parameters of the arrhythmic substrate obtained by different modalities to define the preferred method to identify the substrate of VA.

\section{Disclosures}

None.

\section{Open Access}

This article is distributed under the terms of the Creative Commons Attribution 4.0 International License (http://creativecommons.org/licenses/by/4.0/), which permits unrestricted use, distribution, and reproduction in any medium, provided you give appropriate credit to the original author(s) and the source, provide a link to the Creative Commons license, and indicate if changes were made. 


\section{References}

1. Deo R, Albert CM. Epidemiology and genetics of sudden cardiac death. Circulation. 2012;125:620-37.

2. Mozaffarian D, Benjamin EJ, Go AS, Arnett DK, Blaha MJ, Cushman M, et al. Heart disease and stroke statistics-2015 update: A report from the American Heart Association. Circulation. 2015;131(4):e29-322.

3. Bardy GH, Lee KL, Mark DB, Poole JE, Packer DL, Boineau R, et al. Amiodarone or an implantable cardioverter-defibrillator for congestive heart failure. N Engl J Med. 2005;352(3):225-37.

4. Moss AJ, Zareba W, Hall WJ, Klein H, Wilber DJ, Cannom DS, et al. Prophylactic implantation of a defibrillator in patients with myocardial infarction and reduced ejection fraction. $\mathrm{N}$ Engl J Med. 2002;346(12):877-83.

5. Zipes DP, Camm AJ, Borggrefe M, Buxton AE, Chaitman B, Fromer M, et al. ACC/AHA/ESC 2006 guidelines for management of patients with ventricular arrhythmias and the prevention of sudden cardiac death: A report of the American College of Cardiology/American Heart Association Task Force and the European Society of Cardiology Committee for Practice Guidelines (writing committee to develop guidelines for management of patients with ventricular arrhythmias and the prevention of sudden cardiac death): Developed in collaboration with the European Heart Rhythm Association and the Heart Rhythm Society. Circulation. 2006;114(10):e385-484.

6. Cheng A, Zhang Y, Blasco-Colmenares E, Dalal D, Butcher B, Norgard S, et al. Protein biomarkers identify patients unlikely to benefit from primary prevention implantable cardioverter defibrillators: Findings from the Prospective Observational Study of Implantable Cardioverter Defibrillators (PROSE-ICD). Circ Arrhythm Electrophysiol. 2014;7(6):1084-91.

7. Moss AJ, Greenberg H, Case RB, Zareba W, Hall WJ, Brown MW, et al. Long-term clinical course of patients after termination of ventricular tachyarrhythmia by an implanted defibrillator. Circulation. 2004;110(25):3760-5.

8. Moss AJ, Schuger C, Beck CA, Brown MW, Cannom DS, Daubert JP, et al. Reduction in inappropriate therapy and mortality through ICD programming. N Engl J Med. 2012; 367(24):2275-83.

9. Bertini M, Schalij MJ, Bax JJ, Delgado V. Emerging role of multimodality imaging to evaluate patients at risk for sudden cardiac death. Circ Cardiovasc Imaging. 2012;5:525-35.

10. de Haan S, Knaapen P, Beek AM, de Cock CC, Lammertsma AA, van Rossum AC, et al. Risk stratification for ventricular arrhythmias in ischaemic cardiomyopathy: The value of noninvasive imaging. Europace. 2010;12:468-74.

11. Gerson MC, Abdallah M, Muth JN, Costea AI. Will imaging assist in the selection of patients with heart failure for an ICD? JACC Cardiovasc Imaging. 2010;3:101-10.

12. Piers SR, Tao Q, de Riva SM, Siebelink HM, Schalij MJ, van der Geest RJ, et al. CMR-based identification of critical isthmus sites of ischemic and nonischemic ventricular tachycardia. JACC Cardiovasc Imaging. 2014;7:774-84.

13. Andreu D, Berruezo A, Ortiz-Perez JT, Silva E, Mont L, Borras $\mathrm{R}$, et al. Integration of $3 \mathrm{D}$ electroanatomic maps and magnetic resonance scar characterization into the navigation system to guide ventricular tachycardia ablation. Circ Arrhythm Electrophysiol. 2011;4:674-83.

14. Tian J, Jeudy J, Smith MF, Jimenez A, Yin X, Bruce PA, et al. Three-dimensional contrast-enhanced multidetector CT for anatomic, dynamic, and perfusion characterization of abnormal myocardium to guide ventricular tachycardia ablations. Circ Arrhythm Electrophysiol. 2010;3:496-504.
15. Tian J, Smith MF, Ahmad G, Dilsizian V, Jimenez A, Dickfeld T. Integration of 3-dimensional scar models from SPECT to guide ventricular tachycardia ablation. J Nucl Med. 2012;53:894-901.

16. Dickfeld T, Lei P, Dilsizian V, Jeudy J, Dong J, Voudouris A, et al. Integration of three-dimensional scar maps for ventricular tachycardia ablation with positron emission tomography-computed tomography. JACC Cardiovasc Imaging. 2008;1:73-82.

17. Klein T, Abdulghani M, Smith M, Huang R, Asoglu R, Remo $\mathrm{BF}$, et al. Three-dimensional 123I-meta-iodobenzylguanidine cardiac innervation maps to assess substrate and successful ablation sites for ventricular tachycardia: Feasibility study for a novel paradigm of innervation imaging. Circ Arrhythm Electrophysiol. 2015;8:583-91.

18. de Bakker J, van Rijen H. Mechanisms of ventricular tachycardia: Underlying pathological and physiological abnormalities. In: Wang P, Al-Ahmad A, Hsia H, editors. Ventricular arrhythmias and sudden cardiac death. 1st ed. Malden: Blackwell; 2008. p. $18-27$.

19. Myerburg RJ, Junttila MJ. Sudden cardiac death caused by coronary heart disease. Circulation. 2012;125:1043-52.

20. Furukawa T, Bassett AL, Furukawa N, Kimura S, Myerburg RJ. The ionic mechanism of reperfusion-induced early afterdepolarizations in feline left ventricular hypertrophy. J Clin Invest. 1993;91:1521-31.

21. Luqman N, Sung RJ, Wang CL, Kuo CT. Myocardial ischemia and ventricular fibrillation: Pathophysiology and clinical implications. Int J Cardiol. 2007;119:283-90.

22. Elhendy A, Sozzi FB, van Domburg RT, Bax JJ, Geleijnse ML, Roelandt JR. Relation among exercise-induced ventricular arrhythmias, myocardial ischemia, and viability late after acute myocardial infarction. Am J Cardiol. 2000;86:723-9.

23. Margonato A, Mailhac A, Bonetti F, Vicedomini G, Fragasso G, Landoni $\mathrm{C}$, et al. Exercise-induced ischemic arrhythmias in patients with previous myocardial infarction: Role of perfusion and tissue viability. J Am Coll Cardiol. 1996;27:593-8.

24. Stevenson WG, Weiss JN, Wiener I, Nademanee K. Slow conduction in the infarct scar: Relevance to the occurrence, detection, and ablation of ventricular reentry circuits resulting from myocardial infarction. Am Heart J. 1989;117:452-67.

25. Zaman S, Kovoor P. Sudden cardiac death early after myocardial infarction: Pathogenesis, risk stratification, and primary prevention. Circulation. 2014;129:2426-35.

26. Bello D, Fieno DS, Kim RJ, Pereles FS, Passman R, Song G, et al. Infarct morphology identifies patients with substrate for sustained ventricular tachycardia. J Am Coll Cardiol. 2005; 45:1104-8.

27. Ashikaga H, Sasano T, Dong J, Zviman MM, Evers R, Hopenfeld $\mathrm{B}$, et al. Magnetic resonance-based anatomical analysis of scarrelated ventricular tachycardia: Implications for catheter ablation. Circ Res. 2007;101:939-47.

28. Rijnierse MT, de Haan S, Harms HJ, Robbers LF, Wu L, Danad I, et al. Impaired hyperemic myocardial blood flow is associated with inducibility of ventricular arrhythmia in ischemic cardiomyopathy. Circ Cardiovasc Imaging. 2014;7:20-30.

29. Zipes DP. Influence of myocardial ischemia and infarction on autonomic innervation of heart. Circulation. 1990;82:1095-105.

30. Calkins H, Allman K, Bolling S, Kirsch M, Wieland D, Morady $\mathrm{F}$, et al. Correlation between scintigraphic evidence of regional sympathetic neuronal dysfunction and ventricular refractoriness in the human heart. Circulation. 1993;88:172-9.

31. Podrid PJ. Role of the sympathetic nervous system in the genesis of ventricular arrhythmia. Circulation. 1990;82:103-13.

32. Vaseghi M, Lux RL, Mahajan A, Shivkumar K. Sympathetic stimulation increases dispersion of repolarization in humans with 
myocardial infarction. Am J Physiol Heart Circ Physiol. 2012;302:H1838-46.

33. Kammerling JJ, Green FJ, Watanabe AM, Inoue H, Barber MJ, Henry DP, et al. Denervation supersensitivity of refractoriness in noninfarcted areas apical to transmural myocardial infarction. Circulation. 1987;76:383-93.

34. Cao JM, Fishbein MC, Han JB, Lai WW, Lai AC, Wu TJ, et al. Relationship between regional cardiac hyperinnervation and ventricular arrhythmia. Circulation. 2000;101:1960-9.

35. Chen PS, Chen LS, Cao JM, Sharifi B, Karagueuzian HS, Fishbein MC. Sympathetic nerve sprouting, electrical remodeling and the mechanisms of sudden cardiac death. Cardiovasc Res. 2001;50:409-16

36. Nuss HB, Kaab S, Kass DA, Tomaselli GF, Marban E. Cellular basis of ventricular arrhythmias and abnormal automaticity in heart failure. Am J Physiol. 1999;277:H80-91.

37. Tomaselli GF, Zipes DP. What causes sudden death in heart failure? Circ Res. 2004;95:754-63.

38. Partington SL, Kwong RY, Dorbala S. Multimodality imaging in the assessment of myocardial viability. Heart Fail Rev. 2011;16:381-95.

39. Roes SD, Kaandorp TA, Marsan NA, Westenberg JJ, DibbetsSchneider P, Stokkel MP, et al. Agreement and disagreement between contrast-enhanced magnetic resonance imaging and nuclear imaging for assessment of myocardial viability. Eur J Nucl Med Mol Imaging. 2009;36:594-601.

40. Gradel C, Jain D, Batsford WP, Wackers FJ, Zaret BL. Relationship of scar and ischemia to the results of programmed electrophysiological stimulation in patients with coronary artery disease. J Nucl Cardiol. 1997;4:379-86.

41. Sellers TD, Beller GA, Gibson RS, Watson DD, DiMarco JP. Prevalence of ischemia by quantitative thallium-201 scintigraphy in patients with ventricular tachycardia or fibrillation inducible by programmed stimulation. Am J Cardiol. 1987;59:828-32.

42. McFarland TM, McCarthy DM, Makler PT Jr, Josephson ME. Relation between site of origin of ventricular tachycardia and relative left ventricular myocardial perfusion and wall motion. Am J Cardiol. 1983;51:1329-33.

43. Zhou Y, Zhou W, Folks RD, Manatunga DN, Jacobson AF, Bax JJ, et al. I-123 mIBG and Tc-99m myocardial SPECT imaging to predict inducibility of ventricular arrhythmia on electrophysiology testing: A retrospective analysis. J Nucl Cardiol. 2014;21:913-20.

44. Paganelli F, Barnay P, Imbert-Joscht I, Gelisse R, Saadjian A, Mundler $\mathrm{O}$, et al. Influence of residual myocardial ischaemia on induced ventricular arrhythmias following a first acute myocardial infarction. Eur Heart J. 2001;22:1931-7.

45. Knaapen P, de Haan S, Hoekstra OS, Halbmeijer R, Appelman YE, Groothuis JG, et al. Cardiac PET-CT: Advanced hybrid imaging for the detection of coronary artery disease. Neth Heart J. 2010;18:90-8.

46. Danad I, Raijmakers PG, Knaapen P. Diagnosing coronary artery disease with hybrid PET/CT: It takes two to tango. J Nucl Cardiol. 2013;20:874-90.

47. Bol A, Melin JA, Vanoverschelde JL, Baudhuin T, Vogelaers D, De PM, et al. Direct comparison of [13N]ammonia and [15O]water estimates of perfusion with quantification of regional myocardial blood flow by microspheres. Circulation. 1993;87(2):512-25.

48. Iida H, Tamura Y, Kitamura K, Bloomfield PM, Eberl S, Ono Y. Histochemical correlates of (15)O-water-perfusable tissue fraction in experimental canine studies of old myocardial infarction. J Nucl Med. 2000;41:1737-45.

49. Kaufmann PA, Camici PG. Myocardial blood flow measurement by PET: Technical aspects and clinical applications. J Nucl Med. 2005;46:75-88.
50. Schinkel AF, Poldermans D, Elhendy A, Bax JJ. Assessment of myocardial viability in patients with heart failure. J Nucl Med. 2007; $48: 1135-46$.

51. Brunken R, Tillisch J, Schwaiger M, Child JS, Marshall R, Mandelkern M, et al. Regional perfusion, glucose metabolism, and wall motion in patients with chronic electrocardiographic Q wave infarctions: Evidence for persistence of viable tissue in some infarct regions by positron emission tomography. Circulation. 1986;73:951-63.

52. Maes A, Flameng W, Nuyts J, Borgers M, Shivalkar B, Ausma J, et al. Histological alterations in chronically hypoperfused myocardium. Correlation with PET findings. Circulation. 1994;90: $735-45$.

53. Kuhl HP, Beek AM, van der Weerdt AP, Hofman MB, Visser CA, Lammertsma AA, et al. Myocardial viability in chronic ischemic heart disease: Comparison of contrast-enhanced magnetic resonance imaging with (18)F-fluorodeoxyglucose positron emission tomography. J Am Coll Cardiol. 2003;41:1341-8.

54. Klein C, Nekolla SG, Bengel FM, Momose M, Sammer A, Haas $\mathrm{F}$, et al. Assessment of myocardial viability with contrast-enhanced magnetic resonance imaging: Comparison with positron emission tomography. Circulation. 2002;105:162-7.

55. Tian J, Smith MF, Chinnadurai P, Dilsizian V, Turgeman A, Abbo A, et al. Clinical application of PET/CT fusion imaging for three-dimensional myocardial scar and left ventricular anatomy during ventricular tachycardia ablation. J Cardiovasc Electrophysiol. 2009;20:567-604.

56. Fahmy TS, Wazni OM, Jaber WA, Walimbe V, Di BL, Elayi CS, et al. Integration of positron emission tomography/computed tomography with electroanatomical mapping: A novel approach for ablation of scar-related ventricular tachycardia. Heart Rhythm. 2008;5:1538-45.

57. Camici P, Araujo LI, Spinks T, Lammertsma AA, Kaski JC, Shea $\mathrm{MJ}$, et al. Increased uptake of 18F-fluorodeoxyglucose in postischemic myocardium of patients with exercise-induced angina. Circulation. 1986;74:81-8.

58. Canty JM Jr, Suzuki G, Banas MD, Verheyen F, Borgers M, Fallavollita JA. Hibernating myocardium: Chronically adapted to ischemia but vulnerable to sudden death. Circ Res. 2004;94(8): 1142-9.

59. Canty JM Jr, Fallavollita JA. Hibernating myocardium. J Nucl Cardiol. 2005;12:104-19.

60. Bito V, Heinzel FR, Weidemann F, Dommke C, van DV, Verbeken $\mathrm{E}$, et al. Cellular mechanisms of contractile dysfunction in hibernating myocardium. Circ Res. 2004;94:794-801.

61. Fallavollita JA, Jacob S, Young RF, Canty JM Jr. Regional alterations in SR $\mathrm{Ca}(2+)$-ATPase, phospholamban, and HSP-70 expression in chronic hibernating myocardium. Am J Physiol. 1999;277:H1418-28.

62. Krause BJ, Poeppel TD, Reinhardt M, Vester EG, Yong M, Mau $\mathrm{J}$, et al. Myocardial perfusion/metabolism mismatch and ventricular arrhythmias in the chronic post infarction state. Nuklearmedizin. 2005;44:69-75.

63. Fallavollita JA, Heavey BM, Luisi AJ Jr, Michalek SM, Baldwa $\mathrm{S}$, Mashtare TL Jr, et al. Regional myocardial sympathetic denervation predicts the risk of sudden cardiac arrest in ischemic cardiomyopathy. J Am Coll Cardiol. 2014;63:141-9.

64. Luisi AJ Jr, Suzuki G, Dekemp R, Haka MS, Toorongian SA, Canty JM Jr, et al. Regional 11C-hydroxyephedrine retention in hibernating myocardium: Chronic inhomogeneity of sympathetic innervation in the absence of infarction. J Nucl Med. 2005;46:1368-74.

65. Thackeray JT, Bengel FM. Assessment of cardiac autonomic neuronal function using PET imaging. J Nucl Cardiol. 2013;20:150-65. 
66. Eisenhofer G, Esler MD, Meredith IT, Ferrier C, Lambert G, Jennings G. Neuronal re-uptake of noradrenaline by sympathetic nerves in humans. Clin Sci (Lond). 1991;80:257-63.

67. Eisenhofer G. The role of neuronal and extraneuronal plasma membrane transporters in the inactivation of peripheral catecholamines. Pharmacol Ther. 2001;91:35-62.

68. Travin MI. Cardiac autonomic imaging with SPECT tracers. J Nucl Cardiol. 2013;20:128-43.

69. Werner RA, Rischpler C, Onthank D, Lapa C, Robinson S, Sammnick S, et al. Retention Kinetics of the 18F-labeled Sympathetic Nerve PET Tracer LMI1195: Comparison with 11CHED and 123I-MIBG. J Nucl Med. 2015;56:1429-33.

70. Carrio I, Cowie MR, Yamazaki J, Udelson J, Camici PG. Cardiac sympathetic imaging with $\mathrm{mIBG}$ in heart failure. JACC Cardiovasc Imaging. 2010;3:92-100.

71. Simoes MV, Barthel P, Matsunari I, Nekolla SG, Schomig A, Schwaiger M, et al. Presence of sympathetically denervated but viable myocardium and its electrophysiologic correlates after early revascularised, acute myocardial infarction. Eur Heart J. 2004;25:551-7.

72. Bax JJ, Kraft O, Buxton AE, Fjeld JG, Parizek P, Agostini D, et al. 123 I-mIBG scintigraphy to predict inducibility of ventricular arrhythmias on cardiac electrophysiology testing: A prospective multicenter pilot study. Circ Cardiovasc Imaging. 2008;1:131-40.

73. Harms HJ, de Haan S, Knaapen P, Allaart CP, Rijnierse MT, Schuit RC, et al. Quantification of $[(11) C]$-meta-hydroxyephedrine uptake in human myocardium. EJNMMI Res. 2014;4:52.

74. Bengel FM. Imaging targets of the sympathetic nervous system of the heart: Translational considerations. J Nucl Med. 2011;52:1167-70.

75. Munch G, Nguyen NT, Nekolla S, Ziegler S, Muzik O, Chakraborty $\mathrm{P}$, et al. Evaluation of sympathetic nerve terminals with $[(11) C]$ epinephrine and [(11)C]hydroxyephedrine and positron emission tomography. Circulation. 2000;101:516-23.

76. Matsunari I, Aoki H, Nomura Y, Takeda N, Chen WP, Taki J, et al. Iodine-123 metaiodobenzylguanidine imaging and carbon11 hydroxyephedrine positron emission tomography compared in patients with left ventricular dysfunction. Circ Cardiovasc Imaging. 2010;3:595-603.

77. Harms HJ, Lubberink M, de Haan S, Knaapen P, Huisman M, Schuit RC, et al. Use of a single 11C-meta-hydroxyephedrine scan protocol for assessing flow-innervation mismatches in patients with ischemic cardiomyopathy. J Nucl Med. 2015;56: 1706-11.

78. Sasano T, Abraham MR, Chang KC, Ashikaga H, Mills KJ, Holt $\mathrm{DP}$, et al. Abnormal sympathetic innervation of viable myocardium and the substrate of ventricular tachycardia after myocardial infarction. J Am Coll Cardiol. 2008;51:2266-75.

79. Lautamaki R, Sasano T, Higuchi T, Nekolla SG, Lardo AC, Holt $\mathrm{DP}$, et al. Multiparametric molecular imaging provides mechanistic insights into sympathetic innervation impairment in the viable infarct border zone. J Nucl Med. 2015;56:457-63.

80. Caldwell JH, Link JM, Levy WC, Poole JE, Stratton JR. Evidence for pre- to postsynaptic mismatch of the cardiac sympathetic nervous system in ischemic congestive heart failure. J Nucl Med. 2008;49:234-41.

81. Rijnierse MT, Allaart CP, de Haan S, Harms HJ, Huisman MC, Wu L et al Sympathetic denervation is associated with microvascular dysfunction in non-infarcted myocardium in patients with cardiomyopathy. Eur Heart J Cardiovasc Imaging 2015.
82. Hartmann F, Ziegler S, Nekolla S, Hadamitzky M, Seyfarth M, Richardt G, et al. Regional patterns of myocardial sympathetic denervation in dilated cardiomyopathy: An analysis using carbon-11 hydroxyephedrine and positron emission tomography. Heart. 1999;81:262-70.

83. Bengel FM, Permanetter B, Ungerer M, Nekolla SG, Schwaiger M. Relationship between altered sympathetic innervation, oxidative metabolism and contractile function in the cardiomyopathic human heart; a non-invasive study using positron emission tomography. Eur Heart J. 2001;22:1594-600.

84. Schafers M, Lerch H, Wichter T, Rhodes CG, Lammertsma AA, Borggrefe M, et al. Cardiac sympathetic innervation in patients with idiopathic right ventricular outflow tract tachycardia. J Am Coll Cardiol. 1998;32:181-6.

85. Mazzadi AN, Andre-Fouet X, Duisit J, Gebuhrer V, Costes N, Chevalier P, et al. Cardiac retention of [11C]HED in genotyped long QT patients: A potential amplifier role for severity of the disease. Am J Physiol Heart Circ Physiol. 2003;285:H1286-93.

86. Kies P, Wichter T, Schafers M, Paul M, Schafers KP, Eckardt L, et al. Abnormal myocardial presynaptic norepinephrine recycling in patients with Brugada syndrome. Circulation. 2004;110:301722.

87. Grothues F, Smith GC, Moon JC, Bellenger NG, Collins P, Klein $\mathrm{HU}$, et al. Comparison of interstudy reproducibility of cardiovascular magnetic resonance with two-dimensional echocardiography in normal subjects and in patients with heart failure or left ventricular hypertrophy. Am J Cardiol. 2002;90:29-34.

88. Vadakkumpadan F, Trayanova N, Wu KC. Image-based left ventricular shape analysis for sudden cardiac death risk stratification. Heart Rhythm. 2014;11:1693-700.

89. Mewton N, Liu CY, Croisille P, Bluemke D, Lima JA. Assessment of myocardial fibrosis with cardiovascular magnetic resonance. J Am Coll Cardiol. 2011;57:891-903.

90. Kim RJ, Fieno DS, Parrish TB, Harris K, Chen EL, Simonetti O, et al. Relationship of MRI delayed contrast enhancement to irreversible injury, infarct age, and contractile function. Circulation. 1999;100(19):1992-2002.

91. Schelbert EB, Hsu LY, Anderson SA, Mohanty BD, Karim SM, Kellman P, et al. Late gadolinium-enhancement cardiac magnetic resonance identifies postinfarction myocardial fibrosis and the border zone at the near cellular level in ex vivo rat heart. Circ Cardiovasc Imaging. 2010;3:743-52.

92. Flett AS, Hasleton J, Cook C, Hausenloy D, Quarta G, Ariti C, et al. Evaluation of techniques for the quantification of myocardial scar of differing etiology using cardiac magnetic resonance. JACC Cardiovasc Imaging. 2011;4:150-6.

93. Yan AT, Shayne AJ, Brown KA, Gupta SN, Chan CW, Luu TM, et al. Characterization of the peri-infarct zone by contrast-enhanced cardiac magnetic resonance imaging is a powerful predictor of post-myocardial infarction mortality. Circulation. 2006;114:32-9.

94. de Haan S, Meijers TA, Knaapen P, Beek AM, van Rossum AC, Allaart CP. Scar size and characteristics assessed by CMR predict ventricular arrhythmias in ischaemic cardiomyopathy: Comparison of previously validated models. Heart. 2011;97: 1951-6.

95. Scott PA, Rosengarten JA, Curzen NP, Morgan JM. Late gadolinium enhancement cardiac magnetic resonance imaging for the prediction of ventricular tachyarrhythmic events: A metaanalysis. Eur J Heart Fail. 2013;15:1019-27.

96. Schmidt A, Azevedo CF, Cheng A, Gupta SN, Bluemke DA, Foo $\mathrm{TK}$, et al. Infarct tissue heterogeneity by magnetic resonance imaging identifies enhanced cardiac arrhythmia susceptibility in 
patients with left ventricular dysfunction. Circulation. 2007;115: 2006-14.

97. Nazarian S, Bluemke DA, Lardo AC, Zviman MM, Watkins SP, Dickfeld TL, et al. Magnetic resonance assessment of the substrate for inducible ventricular tachycardia in nonischemic cardiomyopathy. Circulation. 2005;112:2821-5.

98. Fernandez-Armenta J, Berruezo A, Andreu D, Camara O, Silva E, Serra L, et al. Three-dimensional architecture of scar and conducting channels based on high resolution ce-CMR: Insights for ventricular tachycardia ablation. Circ Arrhythm Electrophysiol. 2013;6:528-37.

99. Dickfeld T, Tian J, Ahmad G, Jimenez A, Turgeman A, Kuk R, et al. MRI-Guided ventricular tachycardia ablation: Integration of late gadolinium-enhanced 3D scar in patients with implantable cardioverter-defibrillators. Circ Arrhythm Electrophysiol. 2011;4:172-84.

100. Sasaki T, Miller CF, Hansford R, Yang J, Caffo BS, Zviman $\mathrm{MM}$, et al. Myocardial structural associations with local electrograms: A study of postinfarct ventricular tachycardia pathophysiology and magnetic resonance-based noninvasive mapping. Circ Arrhythm Electrophysiol. 2012;5:1081-90.

101. Desjardins B, Crawford T, Good E, Oral H, Chugh A, Pelosi F, et al. Infarct architecture and characteristics on delayed enhanced magnetic resonance imaging and electroanatomic mapping in patients with postinfarction ventricular arrhythmia. Heart Rhythm. 2009;6:644-51.

102. Perez-David E, Arenal A, Rubio-Guivernau JL, del CR, Atea L, Arbelo E, et al. Noninvasive identification of ventricular tachycardia-related conducting channels using contrast-enhanced magnetic resonance imaging in patients with chronic myocardial infarction: Comparison of signal intensity scar mapping and endocardial voltage mapping. J Am Coll Cardiol. 2011;57:184-94.

103. Gupta S, Desjardins B, Baman T, Ilg K, Good E, Crawford T, et al. Delayed-enhanced MR scar imaging and intraprocedural registration into an electroanatomical mapping system in postinfarction patients. JACC Cardiovasc Imaging. 2012;5:207-10.

104. Andreu D, Ortiz-Perez JT, Boussy T, Fernandez-Armenta J, de Caralt TM, Perea RJ, et al. Usefulness of contrast-enhanced cardiac magnetic resonance in identifying the ventricular arrhythmia substrate and the approach needed for ablation. Eur Heart J. 2014;35:1316-26.

105. Ng J, Jacobson JT, Ng JK, Gordon D, Lee DC, Carr JC, et al. Virtual electrophysiological study in a 3-dimensional cardiac magnetic resonance imaging model of porcine myocardial infarction. J Am Coll Cardiol. 2012;60:423-30.

106. Aus dem SF, Buss SJ, Messroghli D, Andre F, Lossnitzer D, Seitz S, et al. T1 mapping in dilated cardiomyopathy with cardiac magnetic resonance: Quantification of diffuse myocardial fibrosis and comparison with endomyocardial biopsy. Eur Heart J Cardiovasc Imaging. 2015;16(2):210-6.
107. Dass S, Suttie JJ, Piechnik SK, Ferreira VM, Holloway CJ, Banerjee R, et al. Myocardial tissue characterization using magnetic resonance noncontrast t1 mapping in hypertrophic and dilated cardiomyopathy. Circ Cardiovasc Imaging. 2012;5:72633.

108. Iles L, Pfluger H, Phrommintikul A, Cherayath J, Aksit P, Gupta $\mathrm{SN}$, et al. Evaluation of diffuse myocardial fibrosis in heart failure with cardiac magnetic resonance contrast-enhanced T1 mapping. J Am Coll Cardiol. 2008;52:1574-80.

109. Chan W, Duffy SJ, White DA, Gao XM, Du XJ, Ellims AH, et al. Acute left ventricular remodeling following myocardial infarction: Coupling of regional healing with remote extracellular matrix expansion. JACC Cardiovasc Imaging. 2012;5:884-93.

110. Spach MS, Boineau JP. Microfibrosis produces electrical load variations due to loss of side-to-side cell connections: A major mechanism of structural heart disease arrhythmias. Pacing Clin Electrophysiol. 1997;20:397-413.

111. Chen Z, Sohal M, Voigt T, Sammut E, Tobon-Gomez C, Child $\mathrm{N}$, et al. Myocardial tissue characterization by cardiac magnetic resonance imaging using T1 mapping predicts ventricular arrhythmia in ischemic and non-ischemic cardiomyopathy patients with implantable cardioverter-defibrillators. Heart Rhythm. 2015;12:792-801.

112. Truong QA, Thai WE, Wai B, Cordaro K, Cheng T, Beaudoin J, et al. Myocardial scar imaging by standard single-energy and dual-energy late enhancement CT: Comparison with pathology and electroanatomic map in an experimental chronic infarct porcine model. J Cardiovasc Comput Tomogr. 2015;9:313-20.

113. Gerber BL, Belge B, Legros GJ, Lim P, Poncelet A, Pasquet A, et al. Characterization of acute and chronic myocardial infarcts by multidetector computed tomography: Comparison with contrast-enhanced magnetic resonance. Circulation. 2006;113:82333.

114. Deseive S, Bauer RW, Lehmann R, Kettner M, Kaiser C, Korkusuz $\mathrm{H}$, et al. Dual-energy computed tomography for the detection of late enhancement in reperfused chronic infarction: A comparison to magnetic resonance imaging and histopathology in a porcine model. Invest Radiol. 2011;46(7):450-6.

115. Brodoefel H, Klumpp B, Reimann A, Fenchel M, Heuschmid M, Miller S, et al. Sixty-four-MSCT in the characterization of porcine acute and subacute myocardial infarction: Determination of transmurality in comparison to magnetic resonance imaging and histopathology. Eur J Radiol. 2007;62:235-46.

116. Buecker A, Katoh M, Krombach GA, Spuentrup E, Bruners P, Gunther RW, et al. A feasibility study of contrast enhancement of acute myocardial infarction in multislice computed tomography: Comparison with magnetic resonance imaging and gross morphology in pigs. Invest Radiol. 2005;40:700-4. 